\title{
UNA PERSPECTIVA HISTÓRICA SOBRE LA FORMACIÓN DE MAESTROS DE CIENCIAS NATURALES EN COLOMBIA
}

\author{
Ana Barrios Estrada \\ Universidad de Nariño \\ Grupo de Investigación para el Desarrollo \\ de la educación y la pedagogía. GIDEP \\ anitabaes@gmail.com
}

\begin{abstract}
RESUMEN
Este artículo de reflexión presenta la revisión realizada sobre la formación de maestros de Ciencias Naturales en Colombia, con el propósito de entender sus dinámicas y develar posibles orígenes de la tensión entre pedagogía y Ciencias naturales. En tal sentido, se revisaron fuentes documentales desde una perspectiva analítica, lo que permitió el reconocimiento, en un primer momento, de la relación maestro/estudiante que, luego, con la multiplicación de las escuelas, se orienta a una formación pedagógica y científica de maestros para la instrucción pública que, más adelante, se constituiría en la formación de Licenciados en Ciencias Naturales.

Se concluye que, en la historia de la formación en Ciencias Naturales, en Colombia, se encuentran simultáneamente avances, discontinuidades, dificultades, limitaciones y anhelos, que permiten comprender el origen y las diferentes manifestaciones de la tensión entre pedagogía y Ciencias Naturales, en cada uno de los momentos históricos.
\end{abstract}

Palabras clave: Formación, Ciencias Naturales, Historia. 


\title{
AN HISTORICAL PERSPECTIVE ON THE EDUCATION OF TEACHERS OF NATURAL SCIENCES IN COLOMBIA
}

\begin{abstract}
This reflection article presents a review of the training of teachers of Natural Sciences in Colombia, in order to understand their dynamics and reveal possible sources of tension between Pedagogy and Natural Sciences. In this regard, documentary sources were reviewed from an analytical perspective, allowing the recognition, at first, of the teacher/student relationship, which then with the multiplication of schools, aims at a pedagogical and scientific training of teachers for public instruction, which later, would become the formation of Graduates in Natural Sciences.

This article concludes that in the history of education in Natural Sciences in Colombia, progress, gaps, challenges, limitations and desires have taken place simultaneously, allowing an understanding of the origin and different manifestations of the tension between pedagogy and Natural Sciences in each historical moment.
\end{abstract}

Keywords: Education, Natural Sciences, History.

\section{UMA PERSPECTIVA HISTÓRICA SOBRE A FORMAÇÃO DE PROFESSORES DE CIÊNCIAS NATURAIS NA COLOMBIA}

\begin{abstract}
RESUMO
Este artigo de reflexão apresenta a revisão realizada sobre à formação de professores de Ciencias Naturais na Colombia, com o propósito de entender suas dinámicas e revelar possíveis origens das fontes de tensão entre pedagogía e Ciências naturais . A este respeito, fontes documentais foram revisadas a partir da perspectiva de análise, o que permitiu o reconhecimento, em um primeiro momento, da relação professor/estudante que, logo, com a multiplicação das escolas, está orientada a uma formação pedagógica e científica de professores para o ensino público que, mais tarde, se constitui na formação de Licenciados en Ciências Naturais.

Conclui-ר-se que, na historia da formação em Ciências Naturais, na Colômbia, encontra-se simultáneamente avanços, descontinuidades, dificuldades, limitações e anseios, que permiten compreender a origem e diferentes manifestações da tensão entre pedagogía e Ciências Naturais, em cada um dos momentos históricos.
\end{abstract}

Palavras chave: Formação, Ciências Naturais, Historia 


\section{INTRODUCCIÓN}

En este artículo, se parte de reconocer los esfuerzos y avances alcanzados por investigadores, educadores e instituciones, que precedieron esta búsqueda, por lo que se pretende crear continuidades que establezcan vínculos entre pasado, presente y porvenir como horizonte que guíe a las nuevas generaciones hacia una formación cada vez mejor para los Licenciados en Ciencias Naturales, de Colombia.

Se asume esta aproximación histórica tratando de seguir las recomendaciones de Zuluaga y Martínez Boom (1996-1997), en el sentido de reconocer lo particular y lo constante en las prácticas pedagógicas y la educación, como parte de la práctica social, que no siempre obedecen al ritmo de los cambios sociales.

Surge, entonces, la necesidad de estudiar la formación de Licenciados en Ciencias Naturales en Colombia, desde una perspectiva histórica, con el propósito de comprender sus dinámicas y develar posibles orígenes de la tensión entre pedagogía y Ciencias Naturales, asumida como problemática central de la investigación doctoral ${ }^{1}$ realizada por la autora.

El interés por el conocimiento científico, la formación de maestros idóneos para formar a la juventud con motivaciones hacia la investigación y el conocimiento de la ciencia, data de la época colonial, cuando José Celestino Mutis abrió este espacio y produjo impacto en la juventud criolla, en ese entonces, como uno de los promotores de la relación maestro/discípulo en la formación en ciencias.

En este marco, aparece en estas tierras un nuevo oficio ${ }^{2}$, el de maestro, vinculado al surgimiento de la escuela como un acontecimiento singular que, según Zuluaga, "genera un impacto significativo en el orden del aprendizaje que sitúa a la educación en el campo del saber y el poder"3.

Con los procesos de independencia, se configuran los nuevos Estados junto a los proyectos de nación, en los que era importante, para las élites de la época, formar a los nuevos ciudadanos en una cultura que rompiera con el legado español, pero sin reconocer las culturas ancestrales. Así, depositaron su esperanza en la formación científica y en la instrucción pública, que se intentó desarrollar en el transcurso del siglo XIX, lo que da lugar a tensiones entre ciencias tradicionales

1. Se refiere a la tesis doctoral: La tensión disciplinar entre pedagogía y Ciencias Naturales en la formación de Licenciados: Universidad de Nariño, realizada en el Doctorado en Ciencias de la Educación, en la Universidad del Cauca/RUDECOLOMBIA, 2014.

2. Se toma la categoría introducida por Oscar Saldarriaga, en su texto Del oficio del maestro.

3. Olga Lucía Zuluaga 
y "ciencias útiles"; así como entre la Iglesia y el Estado. Se le asigna al maestro la responsabilidad de la formación científica del nuevo ciudadano y se lo considera como "sujeto que imparte enseñanza, el saber pedagógico instituido y el saber producido en el acontecer de las prácticas..." .

El Siglo XX trae la formación de Licenciados en Ciencias, en un contexto donde se trata de responder, desde la educación, a los nuevos retos de modernización, centralización y desarrollos de la economía impuestos por el Estado colombiano. Surgen los grandes debates nacionales en torno al problema educativo, a la formación de maestros idóneos, que movilizaron a los intelectuales del país y dieron paso a un periodo donde a la educación se la piensa como "instrumento ideológico o como mecanismo de dominación" ${ }^{\prime 5}$, renovado en las políticas educativas y la configuración del sistema educativo colombiano homogenizador, que ha desconocido la condición multicultural y pluriétnica de Colombia.

Hacen su incursión las Ciencias de la Educación, que han estado presentes en Colombia, desde principios del siglo XX, relacionadas con la formación de maestros; trajeron consigo el desplazamiento del saber pedagógico, trabajado desde la pedagogía pestalozziana, por la pedagogía entendida como una de las Ciencias de la educación, en relación con las Ciencias sociales y naturales, basadas en los métodos experimentales ${ }^{6}$.

En este contexto, se crean las Facultades de Ciencias de la Educación, que configuraron nuevas prácticas de saber y de poder para la formación de maestros, que se consolidan con la creación de dos universidades pedagógicas que, a mediados del siglo XX, gradúan a maestros con título de Licenciado.

Las tendencias en la formación de maestros, en este periodo, se mueven en diferentes direcciones, producto de la tensión disciplinar entre pedagogía y Ciencias naturales en la formación de Licenciados, que oscilaba entre otorgarle un mayor peso a la formación pedagógica o a la formación científica.

A partir de la década del sesenta, tiene lugar otra ruptura en el trayecto que se traía desde finales del siglo XIX, al determinarse una clara tendencia pragmatista en la formación de Licenciados, donde las Facultades de Educación debían priorizar lo curricular y la planeación, lo que ocasiona un desplazamiento de la pedagogía, tanto en programas de formación e investigaciones educativas de las

4. Olga Lucía Zuluaga y Alberto Martínez Boom.

5. Zuluaga y Martínez Boom,

6. Rafael 
universidades y Facultades, como en prácticas pedagógicas de los maestros en las escuelas, que llevaron a instrumentalizar la enseñanza y a limitar la educación a marcos definidos desde proyectos económicos ${ }^{7}$, ante lo cual las décadas del setenta y ochenta se caracterizaron por las posiciones divergentes que asumen los maestros desde el Movimiento Pedagógico.

Se continua en la década del noventa con una clara intención de cambio a partir de la Constitución Política de 1991, en la que se definieron criterios para orientar los programas de formación de educadores y fortalecer la investigación pedagógica; formar científicos y expertos en educación, con identidad ética y pedagógica, como una de las misiones de las Facultades de Educación. Así, maestros, instituciones de formación e investigadores, trabajan en dirección al cambio educativo, como protagonistas en la construcción del saber pedagógico, la educación en Ciencias, el avance de la ciencia en Colombia, con el surgimiento de los grupos de investigación, hasta la actualidad.

\section{PLANTEAMIENTO DEL PROBLEMA}

Existe una problemática recurrente en la historia de la formación de Licenciados en Ciencias, que se evidencia en una tensión de tipo disciplinar entre quienes tienen a su cargo la enseñanza de las Ciencias naturales y quienes orientan el saber pedagógico, tensión que se explicita en las decisiones curriculares, en los enfoques educativos y en las estrategias pedagógicas, que inciden directamente en el sentido de la formación de los Licenciados y, con ello, en el campo de la Educación en Ciencias Naturales.

Este estudio surge, entonces, de la preocupación por profundizar, desde una perspectiva histórica, en el conocimiento de esta problemática, que es compleja y poco estudiada, no obstante que su presencia, en la formación de educadores, ha sido constante, con diferentes matices e implicaciones en la dinámica curricular, en la praxis del docente universitario y en el posterior desempeño profesional de los educadores, que enfrentan el debilitamiento de su identidad profesional.

Se desarrolla a continuación un posible itinerario de acontecimientos que entrañan la formación de maestros en Ciencias Naturales en Colombia, que no es lineal, ni exenta de rupturas, ya que se trata de comprender algunas formas de poder, pensar y actuar que han definido el devenir de lo que se puede considerar como educación en Ciencias, entendida desde el surgimiento de la escuela, el

7. Magnolia 
maestro, su saber y su formación, junto con algunos hitos de la historia social de la ciencia y la tecnología, que han tenido lugar en Colombia.

\section{DESARROLLO}

\subsection{Relación maestro/discípulo en la formación de maestros en Ciencias Naturales}

La irrupción política y cultural hispánica en América hace que la historia de la formación de maestros en Colombia se presente de manera incipiente desde los primeros siglos de dominación, la que se inicia con un desconocimiento, a su vez, de la educación, los saberes y los maestros de las culturas ancestrales americanas, lo que crea una ruptura con ellas, por la imposición que se dio, en el marco colonial, que puso a la educación en manos de la Iglesia ${ }^{8}$, que afianzó sus relaciones con la monarquía española, reguladas por el "Real Patronato de Indias"9. Entre 1550 y 1620 se instauraron las comunidades religiosas y educativas que fundan escuelas ${ }^{\mathbf{1 0}} \mathrm{y}$ traen el saber expresado en planes y manuales de enseñanza ${ }^{11}$. En estas escuelas, se pretendió enseñar lecciones de lectura, escritura, aritmética, con especial acento en el catecismo y la religión.

Según los trabajos de Martínez Boom $(1985,1987,1994)$, las escuelas que surgen en el periodo colonial, "como un acontecimiento de saber y de poder distinto a prácticas de enseñanza anteriores al siglo XVIII"12 , respondían a prácticas de exclusión social de los pobres, a los que prepararon para realizar trabajos rudimentarios y para ser policías de oficio; en todo caso, representaban un limitado sector de la población, que se formó desde discursos y prácticas religiosas.

8. "Por medio de cédulas, provisiones y ordenanzas reales y de bulas papales otorgadas a las comunidades y congregaciones religiosas de Jesuitas, Franciscanos y Dominicos para organizar la educación destinada a la formación e instrucción de religiosos y seglares en el Nuevo Reino de Granada" (

9. Aline 2006)), 5 .

10.

11.

12. 
En este contexto, difícilmente se podía abrir paso una formación orientada al conocimiento de la ciencia, que empezó su trayecto en el siglo XVIII, como tampoco un pensamiento pedagógico diferente a la educación escolástica.

En la segunda mitad del siglo XVIII, bajo la influencia del pensamiento ilustrado en la Nueva Granada ${ }^{13}$, se presenta un cambio en la orientación de la educación, que trata de movilizarla de la formación escolástica hacia una educación que se interesa en la ciencia; como lo expresa Ocampo, "los ilustrados tuvieron gran interés por la naturaleza, el conocimiento científico y los métodos experimentales y prácticos" ${ }^{14}$, quienes se caracterizaron por el apasionado estudio de las Ciencias naturales, en especial la botánica y las Ciencias biológicas; junto a la física, la química, las matemáticas, entre otras, lo cual empezó a generar un cambio en la forma de entender el conocimiento, su origen y aplicación, lo que planteó un nuevo tipo de pensamiento: la formación de maestros en ciencias, desde la relación maestro/discípulo.

En ese entonces, se registra la llegada de José Celestino Mutis, en 1760, a la Nueva Granada, quien promovió el ambiente científico, con la instalación de la cátedra de matemáticas, en el Colegio Mayor de Nuestra Señora del Rosario, y de física, cátedras en las que expuso las ideas de Newton, Copérnico y Galileo ${ }^{15}$. Mutis lideró la formación tanto en ciencia como en pedagogía, puesto que pro-

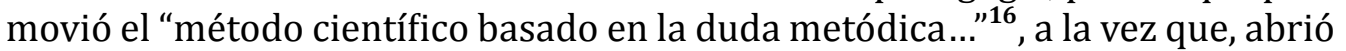
los debates sobre los programas, la forma de enseñar, los métodos de estudio, los contenidos y los textos, con el propósito de transformarlos y enfocarlos hacia una filosofía natural y a las ciencias útiles ${ }^{17}$.

13. En el siglo XVIII, con las reformas borbónicas, inspiradas en la Ilustración, la monarquía española pretendió instaurar una nueva idea de Estado, "cuya meta era la modernización de la nación y la transformación de la sociedad en busca del bienestar general" (Santiago Díaz,

(2005), 117-118), pero se constituyó en lo que se conoce como “Despotismo Ilustrado de Carlos III" (Diana Soto,

$$
\text { 2005), 103). }
$$

14. Javier Ocampo. El Dr. José Félix de Restrepo: el maestro de la generación de la independencia. En: Revista Historia de la Educación Colombiana (6-7) (2004), 15.

15. Además de presentar las nuevas doctrinas Mutis defendió el sistema copernicano. "En los colegios de Santafé aún se enseñaba el sistema de Tolomeo” (Ocampo, El Dr. José Félix de Restrepo: el maestro de la generación de la independencia, 13). Esto casi lo lleva ante la Santa inquisición de Cartagena para ser castigado, según Diana Soto (Mutis y los estudios matemáticos en Santafé de Bogotá. En: Colombia. Revista Ciencias de la Educación (26), 1992).

16. Moisés Wasserman. La ciencia en Colombia en 200 años de vida republicana. En: Colección Colombia 200 años de identidad. Tomo V - Para pensar a Colombia (Bogotá: Universidad Nacional y Publicaciones Semana, 2010), 9.

17. Lo útil entendido como aquel conocimiento que podía servir a los propósitos del Estado. En la España de la segunda mitad del siglo XVIII... predominaban las ciencias útiles -sobre todo las técnicas- frente a las humanidades, pues sólo a través de esas técnicas se piensa que es posible racionalizar la vida social en la agricultura, en el comercio, y en la industria como vía de enriquecimiento del País (Javier Ocampo. Las huellas de Mutis y Humboldt en la ciencia y educación colombianas. En: Revista Historia de la Educación Colombiana (2) (1999), 72-73). 
Así, Mutis trató de socavar la enseñanza escolástica y de promover un cambio en el sistema educativo, apoyado en la experiencia y la indagación; fue ideólogo y director de la Real Expedición Botánica (1783-1816), de la que se destacan como mayores aportes: "el cambio del enfoque curricular imperante en la enseñanza de la ciencia y de las profesiones; la clasificación taxonómica de fauna y flora; las primeras observaciones sociales y la formación de un espíritu ilustrado con una clara... conciencia política" ${ }^{\mathbf{1 8}}$. Mutis, junto a sus discípulos, "aprendieron y cultivaron diversas ciencias, como matemáticas, medicina, botánica, física, química zoología, antropología y otras varias", lo que, según Poveda ${ }^{\mathbf{1 9}}$, origina un movimiento para la construcción de ciencia americana, que contribuyó "a la instauración de la educación en ciencias en lo que hoy es Colombia", según señala Zambrano ${ }^{20}$.

Por tanto, Mutis representa la idea de maestro que imperaba en ese entonces en Europa, relacionada con tener el mérito de hacer ciencia, ser científico, producir conocimiento y, luego, tomar cursos para enseñar. Esta nueva forma de asumir la educación, vinculada a un maestro cuya condición es la del hombre que hace ciencia, como en el caso de Mutis, trae implícitas dos ideas: una, muestra la formación del maestro de ciencias en la relación directa, cotidiana del maestro con el discípulo, que se manifiesta, por ejemplo, en la influencia que tuvo sobre la formación de José Félix de Restrepo, quien, a su vez, fue maestro de Francisco José de Caldas ${ }^{21}$, difusor de las ideas de la ilustración en el Semanario del Nuevo Reino de Granada e introdujo la nueva educación en el seminario de Popayán, durante 29 años, con una enriquecedora labor educativa y se convirtió en el maestro de la generación precursora de la independencia; es decir, en estas experiencias se reconoce la formación del maestro en la relación directa con el aprendizaje de las ciencias, en una relación maestro/discípulo.

La otra idea evidencia "el problema de las tensiones entre las culturas científicas con sus pretensiones de universalidad y los saberes locales que por definición estarían limitados a circunstancias particulares de tiempo y de lugar"22 , que se suscitan con el despliegue de la Real Expedición Botánica. Dichas pretensiones

18.

19. Gabriel

20. Zambrano, 2009, p. 1 .

21.

22. Diana Obregón. Culturas científicas y saberes locales: asimilación, hibridación, resistencia (Bogotá: Universidad Nacional de Colombia, 2000), 11. 
de universalidad pueden ser uno de los orígenes de la tensión entre pedagogía y ciencias, que concede una mayor validez a las ciencias.

En este contexto histórico, surge en la Nueva Granada la primera propuesta "de universidad pública y el Plan ${ }^{23}$ de Estudios del Fiscal Moreno y Escandón para la ciudad de Santafé...." propuso un método desde el eclecticismo y la filosofía ilustrada, que buscó orientar la "enseñanza secundaria y superior hacia una concepción más práctica y hacia las ciencias experimentales" ${ }^{24}$, apoyada en la observación y la experiencia para acceder al conocimiento, lo que implicaba abandonar la educación escolástica, la repetición de lecciones y asumir el conocimiento desde la experiencia, para formar un adecuado juicio y razonamiento. Desde esta perspectiva, se esperaba que el avance en el conocimiento experimental fortaleciera la labor del maestro y su oficio de enseñar, desde una nueva relación entre el conocer y el enseñar. Estos planteamientos dieron lugar a continuos debates en defensa de los nuevos estudios fundamentados en las ciencias experimentales, no sólo por parte de los neogranadinos formados por Mutis y con el plan de Moreno y Escandón, sino como una manifestación de los avances en las Ciencias naturales, que tenían el respaldo de publicaciones y discusiones ${ }^{25}$ de los movimientos intelectuales.

Este es el panorama general de la educación en la Nueva Granada, donde se empezaron a abrir espacios, las nuevas ideas del pensamiento ilustrado y la formación en ciencias, que dieron paso a transformaciones sociales, políticas y culturales que se tradujeron en la emancipación de las colonias de la corona española. No obstante, la generación de jóvenes científicos, que fundamentó

23. D

con lo cual se equipara a la idea de Comenio, de un método para la enseñanza, cuyo propietario va a ser el maestro, según Olga Lucía Zuluaga, quien entiende a la enseñanza como un "acontecimiento cultural y de saber" (Olga Lucía Zuluaga, de "individualización" (Olga Lucía Zuluaga, 1987), 36), que le debe su momento 1993), 119), a la Didáctica Magna de Comenio.

24. Helg, 18.

25. Los alcances de dichas iniciativas y debates se expresaron en los planes propuestos, posteriormente, por el arzobispo virrey Antonio Caballero y Góngora (1787) y Eloy Valenzuela (1806), en los que se reconocía el abandono de la educación, se retomaban los postulados del Plan Moreno, sobre el método de enseñanza, se proponían nuevos estudios, como la botánica y la química. Alexander von Humboldt describía así la atmosfera de la época: existe un movimiento intelectual entre la juventud americana, desconocido en España, que no obstante la prohibición, a los profesores de las escuelas superiores para enseñar la nueva filosofía, como se denomina a la física, mecánica y astronomía, los jóvenes estudian por su cuenta (Luis Carlos Arboleda. Matemáticas, Cultura y Sociedad en Colombia. Historia Social de la Ciencia en Colombia. Tomo II, primera parte (Bogotá: Colciencias, 1993)). 
en la ciencia sus anhelos de independencia y se formó con influencia de este pensamiento, fue exterminada ${ }^{26}$, lo que, así, truncó su participación en la configuración de la nueva República y la posibilidad de construir una pedagogía y ciencias propias, lo que establece una nueva discontinuidad en el desarrollo de la ciencia y de la educación, que puede ser uno de los motivos que, más adelante, dará origen a la tensión entre pedagogía y Ciencias naturales en la formación Licenciados.

\subsection{La formación pedagógica y científica de maestros para la instrucción pública}

Los complejos procesos de cambio que se suscitaron desde la segunda mitad del siglo XVIII, promovidos por los ideales ilustrados y la redefinición de poderes, forjaron un ambiente de renovación e insurrección que no sólo significó la declaración de la independencia y la constitución de la nueva república, sino implicó nuevos desafíos, que persistieron durante todo el siglo XIX, tales como los conflictos políticos y las guerras civiles que se sucedieron y las reformas educativas que fueron parte de la construcción del primer sistema republicano en lo que hoy es Colombia.

Desde los inicios de la vida independiente, la élite criolla entendió que la consolidación del nuevo Estado ${ }^{27}$ exigía cambios, entre los cuales estaba la concepción de la educación pública apoyada en las "ciencias útiles" ${ }^{28}$, lo que suponía la formación de una sociedad en cuya mentalidad radicara la idea de una patria libre y próspera, con un sentido fuerte de independencia y autonomía; para conseguir ese ideal, la educación debía convertirse en el componente imprescindible para la construcción de la nacionalidad.

La clase política, consciente de la realidad de un país en el que la mayoría de su población, salvo sectores de la élite masculina, era analfabeta, entendió

26 “Don Francisco José de Caldas, astrónomo, fue fusilado el 29 de octubre de 1816; Don José Joaquín Camacho, botánico, fue ejecutado el 31 de agosto de ese año; Don José María Carbonell, secretario de la Expedición Botánica, fue ejecutado el 19 de junio; Don Jorge Tadeo Lozano, zoólogo, fue ejecutado el 6 de julio; Don Sinforoso Mutis, botánico y sobrino de José Celestino, fue condenado, pero se le otorgó perdón; Don Miguel de Pombo, botánico, fue ejecutado el 12 de octubre; Don Enrique Umaña, minerólogo, se separó de la posición del grupo y fue nombrado posteriormente funcionario del Real Servicio, y Don Francisco Antonio Zea, botánico, se exilió en Europa; más tarde fue vicepresidente de la Gran Colombia y embajador en Francia, donde tuvo una importante acción en ciencia, pero murió, tempranamente para la República, en 1823" (Wasserman, La ciencia en Colombia en 200 años de vida republicana, 10).

27. La construcción de la nación colombiana se orientó desde el ideal de una nación "para siempre,e irrevocablemente, libre e independiente de la monarquía española y de cualquier otra potencia o dominación extranjera; y no es, ni será nunca el patrimonio de ninguna familia o persona" (Congreso, 1821, p. 291).

28. Diana Soto, Aproximación histórica a la Universidad colombiana. En: Revista Historia de la Educación Latinoamericana (7) (2005), 111. 
la necesidad de crear escuelas de primeras letras; como se expresaba en la Constitución de 1821 del Congreso de Cúcuta ${ }^{29}$, se propuso "establecer en las primeras ciudades de Colombia escuelas normandas del método lancasteriano o de enseñanza mutua, para que desde allí se fueran difundiendo a todas las provincias"30. Un año después, en Bogotá, "se creó la primera Escuela Normal del País, con el objeto de formar profesores, normalizar las prácticas de enseñanza y difundir el sistema de enseñanza mutua" ${ }^{31}$, iniciativa impulsada por Simón Bolívar y Francisco de Paula Santander, convencidos de los beneficios de un sistema que permitía "a un sólo maestro enseñar a mil niños al tiempo, los rudimentos de la moral, la escritura y el cálculo" ${ }^{32}$. Se instaura una nueva relación de comunicación, porque dichas escuelas demandaban la divulgación a gran escala del conocimiento y otro tipo de enseñanza, que obligaba a dejar la relación maestro/ discípulo, uno a uno, para asumir un nuevo papel comunicativo y pedagógico, para lo que se requería organizar instituciones que legitimaran la formación de más maestros, que estuvieran en capacidad de enseñar las "ciencias útiles" a fin de superar la formación artesanal; creían, además, en la importancia de incluir el método en la preparación de los maestros, quienes asumieron el rol de orientar la enseñanza de las personas que tenían el privilegio de asistir a la escuela y se esperaba que, más que personas eruditas, fueran personas virtuosas.

Junto a estas intenciones por transformar la educación, se trató de impulsar la ciencia en la Gran Colombia, por parte de Santander, y con el apoyo de Bolívar, quien aprobó la Misión Científica (1823-1829) ${ }^{33}$, que tuvo entre sus funciones crear el Museo Nacional, denominado, en ese entonces, Museo de Historia Natural, y la Escuela de Minería. En 1826, se dio otra muestra del interés por la

29. "Habrá por lo menos una escuela de primeras letras en todas las ciudades, villas parroquias y pueblos que tuvieren 100 vecinos y de ahí arriba" (Congreso, 1821, p. 158); también, se propuso la formación de maestros preparados para estas escuelas, a fin de contribuir a la construcción del sistema de instrucción elemental público como parte del proceso de institucionalización de la naciente república, que demandó una red de instituciones, sujetos y saberes para que la instrucción pública se constituyera en una estrategia de construcción y afianzamiento de la nación. De esta forma, el Estado asume el control de la escuela como el espacio que tiene como función la enseñanza, que hasta ese entonces pertenecía al ámbito privado de la Iglesia católica y la familia

30. Congreso, 1821, p. 160.

31. Alberto Martínez Boom, Jorge Castro y Carlos Noguera. Crónica del desarraigo, historia del maestro en Colombia (Bogotá: Magisterio, 1989), 37.

32. Oscar Saldarriaga, Javier Sáenz, y Armando Ospina. Mirar la infancia: pedagogía, moral y modernidad en Colombia, 1903-1946 (Bogotá: Colciencias, 1997), 398.

33. Francisco Antonio Zea, como embajador en París, con apoyo de Humboldt, contrató a cuatro científicos franceses y un peruano, Mariano Rivero, ingeniero de minas y químico de la Escuela Real de Minas de París, a quien se encargó de la organización y dirección del Museo de Historia Natural y Escuela de Minería, que se fundó por Ley del primer Congreso de la República, el 28 de julio de 1823, y abrió sus puertas el 4 de julio de 1824, según lo señala Wasserman, La ciencia en Colombia en 200 años de vida republicana, 10 . 
educación y la ciencia, cuando el Congreso, al atender a las propuestas de Santander, expidió la Ley orgánica de educación pública ${ }^{34}$.

Estos fueron esfuerzos definidos para afianzar el control del Estado y romper con la educación colonial y la hegemonía que la Iglesia hasta el momento tenía en la sociedad. No obstante, el sistema educativo continuó con grandes limitaciones, porque sólo podían acceder a ella algunos criollos hombres, considerados ciudadanos; además, en este periodo, los conflictos políticos ${ }^{35}$ no sólo frenaron las aspiraciones educativas reformistas, sino las buenas intenciones de promover la ciencia.

Una vez superados los momentos más críticos de las disputas políticas, se retomó el interés por la educación y las ciencias, en la República de la Nueva Granada, como quedó expresado en la reforma de Mariano Ospina Rodríguez $(1842-1845)^{\mathbf{3 6}}$, quien orientó la educación nuevamente "hacia lo práctico y lo útil" $^{37}$, apoyada en la libertad de enseñanza, que debía privilegiar los conocimientos industriales y las Ciencias exactas y naturales, para garantizar la formación de ciudadanos en profesiones prácticas que impulsaran el desarrollo de la industria $\mathrm{y}$ el aprovechamiento de las riquezas nacionales, como lo expresa Guerrero ${ }^{38}$. Se evidencia un mayor interés en las Ciencias exactas y naturales en la formación de ciudadanos, mientras la pedagogía quedó relegada a un segundo plano.

Otra muestra del renovado interés por la ciencia, en la República de la Nueva Granada, se encuentra en la gestación del proyecto, liderado por el Estado, durante el gobierno de José Hilario López, como lo fue la Comisión Corográfica, que funcionó entre 1850 y 1859, con el objetivo de facilitar el desarrollo del país, mediante el estudio de sus riquezas físicas y humanas. Heredera de la Expedición Botánica, se adecuó a las necesidades del momento, lo que la llevó al redescubrimiento del país, a través de la descripción e inventario de sus riquezas físicas,

34. Que cubría desde el nivel elemental hasta el universitario y emprendió una reforma a la educación, estableció para las escuelas la enseñanza mutua que se ocupaba del aprendizaje de la lectura y escritura, a la vez que estimuló el conocimiento de las artes, las letras, las Ciencias naturales y exactas, la moral y la política; además, se fundó la Academia Nacional de Educación, instalada el mismo día de la creación de la Universidad Central de Bogotá. conformada por veintidós miembros de reconocido prestigio, como Félix de Restrepo, designado director, José Manuel de Restrepo, Vicente Azuero, y otros.

35 El de 1826 a 1832 fue un periodo especialmente crítico en la historia colombiana, porque se dio la revuelta de José Antonio Páez, la disolución del Congreso de Ocaña, los poderes dictatoriales de Bolívar, la conspiración septembrina de Santander y la separación de la Gran Colombia.

36. Reformó el Plan de estudios que se venía aplicando desde 1826 y mantuvo el control de la educación por parte del Estado, en los diferentes niveles, pero le devolvió al clero la influencia sobre la educación en el país, en especial en la Educación Superior (Soto, Aproximación histórica a la Universidad colombiana, 114).

37. Mariano

38. Gerardo León 
humanas y una cartografía que facilitara el desarrollo ${ }^{39}$. Durante el período de la Confederación Granadina ${ }^{40}$, se creó la Sociedad de Naturalistas Neogranadinos, que funcionó entre 1859 y 1861, con doce secciones en las diversas ramas de la ciencia, y se caracterizó ${ }^{41}$ por "su interés exclusivo por impulsar las ciencias naturales sin ocuparse de las consecuencias que el conocimiento útil pudiese tener para moralizar a la población y para mantener el orden social” ${ }^{\mathbf{4 2}}$.

Con la aprobación de la Constitución de Rionegro en 1863, promulgada por los liberales radicales, se estableció la república federada, llamada Estados Unidos de Colombia, constituida por Estados independientes y una presidencia central, con libertades individuales de expresión, pensamiento, enseñanza, culto, entre otras, lo que da paso a uno de los períodos de reforma educativa de gran importancia en la historia del siglo XIX, en todos sus niveles, por sus alcances políticos, culturales y sus realizaciones prácticas, que se apoyaron en una concepción de sistema de enseñanza e instrucción pública, obligatoria y gratuita, entendida como una función del Estado y orientada a la libertad, que se pensaba precedía al progreso ${ }^{43}$. Por otra parte, se promulgó la Ley 30 de 1868, que se destinó a fomentar la "educación pública" a través de la creación de Escuelas Normales, dirigidas a la formación de institutores inteligentes para las escuelas públicas ${ }^{44}$.

En estas circunstancias, el "Estado colombiano adelantó la creación y organización de Escuelas Normales responsables de la formación de maestros con buen sentido pedagógico" ${ }^{\prime 5}$, de tal manera que se reconoció la importancia y la necesidad de la formación de maestros, al decretar la creación de la Escuela

39. Se nombró como director de la comisión al ingeniero y coronel Agustín Codazzi, hombre práctico, que sacó adelante este proyecto, aun en los momentos más difíciles, por falta de recursos. La investigación social fue responsabilidad de don Manuel Ancízar, "intelectual, comerciante y funcionario de los gobiernos radicales y posteriormente nombrado rector fundador de la Universidad Nacional de Colombia”, según señala Wasserman, La ciencia en Colombia en 200 años de vida republicana, 11).

40. Se conoce como el período de la Confederación Granadina (1858 a 1863), a los años en los cuales se trata de cambiar la estructura centralista del Estado, por parte de los conservadores, con la fuerte oposición de los liberales radicales y el estallido de la guerra civil.

41. Considerada como la primera sociedad científica fundada en el país, porque documentó sus realizaciones, se mantuvo en contacto con la comunidad científica europea y continuó con el trabajo iniciado por la primera Expedición Botánica. Por falta de apoyo oficial, tuvo una corta vida.

42. Diana Obregón. La sociedad de naturalistas neogranadinos y la tradición científica. En: Anuario colombiano de historia social y de la cultura, 8 (18-19) (1990-1991), 105.

43. En este momento histórico, la élite política liberal radical creó la Universidad Nacional de Colombia en 1867, con las siguientes Escuelas: Derecho, Medicina, Ciencias naturales, Ingeniería, Artes y oficios y Literatura y filosofía" (Ley 66, 1867, Art. 2º), que, con el tiempo, vendría a ser un espacio de formación profesional sólida y duradera.

44. Se acogieron métodos de enseñanza novedosos, que debían velar por el entendimiento para que los niños puedan descubrir los principios de lo que aprendían, a partir de una enseñanza gradual, que debía respetar el desarrollo natural de la razón; se esperaba conferir a las prácticas educativas unos principios pedagógicos y elementos de las ciencias experimentales, que evitaran la memorización y el saber mecánico, según Decreto Orgánico de Instrucción Pública (DOIP, 1870, Art. 62).

45. Miryam Báez. La formación de maestros en Colombia y Argentina entre 1870-1880. En: Revista Historia de la Educación Colombiana $(3,2)$ (2001), 89. 
Central ${ }^{46}$, en la capital de la unión, para formar maestros idóneos en los métodos de enseñanza de Pestalozzi, quienes irían a dirigir las Escuelas Normales que se crearían, en cada capital de Estado, con criterios pedagógicos y científicos ${ }^{47}$. Para apoyar la creación y organización de las Escuelas Normales de Varones, se trajo a Colombia a la primera Misión pedagógica alemana en 1872, compuesta por nueve educadores formados en las teorías de Pestalozzi y Froebel. Se percibe la intención por recuperar el valor de la pedagogía en la formación de maestros, junto a las Ciencias.

En esta época, se encuentran nuevamente esfuerzos por institucionalizar la actividad científica, en Colombia, asociados a la consolidación de la enseñanza profesional en las universidades y a la creación de academias y sociedades científicas $^{48}$, con actividad permanente hasta entrado el nuevo siglo. En la Sociedad de Ciencias Naturales y Medicina, se destaca, entre sus integrantes, Florentino Vezga (1833-1890), que publicó la Botánica indígena y planteó que "los botánicos de la expedición del siglo XVIII se basaban en el saber indígena"49 ${ }^{\text {, }}$ por eso, como historiador-naturalista, sustentó la necesidad de trazar un programa que preservara la continuidad de los saberes indígenas que aportaron a la expedición Botánica.

La Constitución de $1886^{50}$ establece una reorientación drástica del sistema educativo colombiano, al estipular que "la educación pública será gratuita y no obligatoria... será organizada y dirigida en conformidad con los dogmas y la moral de la Religión Católica ${ }^{51}$. De esta forma, se le devuelve a la Iglesia católica el

46. Institución pedagógica abierta en la ciudad de Bogotá, el 20 de enero de 1872, como Escuela Normal de Varones del Estado de Cundinamarca... con la dirección del pedagogo alemán Ernesto Hotschick y Martín Lleras (La Escuela Normal, Bogotá, Tomo III, № 54, 1872).

47. Donde se enseñaba la aplicación de las ciencias a la agricultura, las artes, oficios y la pedagogía, para aprender la teoría de la enseñanza y el empleo de métodos (DOI, 1870, Arts. 114, 133, 134, 135). Se crean nueve Escuelas Normales "con sus respectivas escuelas anexas, bajo la dirección de los pedagogos alemanes contratados para tal fin en cada capital de los Estados Federados” (Ramón Zapata. Dámaso Zapata o la reforma educacionista en Colombia (Bogotá: Editorial El Gráfico, 1960), 132-134).

48. Entre 1871 y 1873, funcionó la Academia de Ciencias Naturales, y entre 1873 y 1891 . la Sociedad de Ciencias Naturales y Medicina, con publicaciones periódicas. En los años siguientes, los naturalistas se agruparon por sus profesiones: la Sociedad Colombiana de Ingenieros en 1887, la Academia de Medicina en 1891, y la Sociedad Geográfica de Colombia en 1903, según Wasserman, La ciencia en Colombia en 200 años de vida republicana, 15.

49. Obregón, La sociedad de naturalistas neogranadinos y la tradición científica, 113.

50. “En nombre de Dios, fuente suprema de toda autoridad... Y con el fin de afianzar la unidad nacional y asegurar los bienes de la justicia, la libertad y la paz," dirigió la vida constitucional de Colombia desde 1886 hasta 1991. Surgió durante la llamada Regeneración, bajo el mandato de Rafael Núñez, quien se apoyó en el conservador Miguel Antonio de Caro; revocó el federalismo, creó un República unitaria, dividió el poder en tres ramas (legislativa, ejecutiva y judicial), estableció el periodo presidencial de seis años y creó los Departamentos para la administración territorial nacional (Constitución de 1886: Art. $\left.1^{\circ}, 57,114,182\right)$.

51. 
poder en el país y sobre la educación del ciudadano católico ${ }^{52}$, lo que se refrenda con el Concordato, firmado con León XIII, en 1887.

La educación, en el siglo XIX, se sujeta a las luchas políticas partidistas, problemas con la Iglesia, limitaciones presupuestales y guerras civiles, que protagonizaron diferentes sectores dominantes, quienes plantearon múltiples reformas desde el inicio de la vida independiente, con las que trataron de alcanzar el ideal de educación pública del ciudadano, para el impulso y desarrollo económico de una nueva sociedad libre y próspera, con formación científica y moderna enfocada hacia lo práctico y lo útil, que no se logró concretar.

\subsection{La formación de Licenciados en ciencias a partir del siglo $\mathrm{XX}$}

Se entra al siglo XX con la necesidad de superar secuelas dejadas por la Guerra de los Mil Días y con la idea, que se instauró desde finales del siglo anterior, de impulsar la instrucción pública y el desarrollo industrial en el país, que necesitaba responder a los nuevos retos de modernización y centralización que se propuso el Estado colombiano. Se reorganizó la educación con un sentido más pragmático y adecuado a los nuevos desarrollos de la economía, que se expresaron claramente en la Ley 39 de 1903 - Ley Orgánica de Instrucción Pública - conocida como reforma Uribe ${ }^{53}$, según la cual la educación intelectual, debía orientarse al desarrollo y perfeccionamiento de las facultades mentales del niño a través de la espontaneidad del pensamiento. Por tanto, la enseñanza se apoyaría en la intuición, en el espíritu de observación, de reflexión, de invención de los alumnos, quienes debían expresar, sencilla pero adecuadamente, sus propias observaciones y raciocinios. Además, se hace evidente la preocupación por articular la teoría con la práctica y fomentar en los niños la afición a los estudios útiles, que privilegien el aspecto práctico y en correspondencia con

52. "Son ciudadanos los colombianos varones mayores de veintiún años que ejerzan profesión, arte u oficio, o tengan ocupación lícita u otro medio legítimo y conocido de subsistencia” (Constitución de 1886, Art. 15).

53. Esta Ley se caracterizó por asignarle a la educación, la tarea de unificar la nación, centralizar el poder. De tal forma que la educación, en general, según el Decreto reglamentario 491 de 1904, en sus Artículos 46 y 48, quedó definida como moral, intelectual, cívica y física. La Ley orgánica propuso algunas innovaciones, al diferenciar la instrucción profesional y la industrial; al dividir la secundaria en técnica y clásica, por tanto, la Instrucción Pública se dividió en Primaria, Secundaria, Industrial y Profesional (Art. 2º de la Ley 39 de 1903). Se destinaba a "que en el menor tiempo posible y de manera esencialmente práctica se enseñen las nociones elementales, principalmente las que habilitan para el ejercicio de la ciudadanía y preparan para la agricultura, la industria fabril y el comercio." (Art. 3o y Art. 6o de la Ley 39 de 1903. Orgánica de Instrucción Pública - conocida como reforma Uribe, reglamentada por el Decreto 491 de 1904, que se constituyó en el fundamento jurídico del sistema educativo colombiano durante la primera mitad del siglo, "Por cuanto las disposiciones posteriores no cambiaron esencialmente su estructura" (Yvon Lebot. Educación e Ideología en Colombia (Medellín: Editorial La Carreta, 1975), 17.) 
las necesidades de la vida cotidiana y la sociedad ${ }^{54}$. La responsabilidad de la educación era de los maestros ${ }^{55}$.

Llama la atención que, en el Plan de estudios de primaria, aunque ya aparece la formación en ciencias, era muy reducida, porque sólo en el tercer año se abrió un espacio pequeño para la Historia natural ${ }^{56}$, que se mantenía en los dos siguientes años, para finalizar en el sexto año con la enseñanza de la física, que comprendía nociones elementales: propiedades principales de los cuerpos, explicación del barómetro, del termómetro, de las bombas, etc.; explicación de los principales fenómenos de la naturaleza, como la lluvia, el sereno, el rocío, el rayo, el trueno, etc., como lo establece el Capítulo V del Decreto 491 de 1904. La Instrucción Secundaria estaba a cargo de la Nación y se dividía en: clásica, que conducía al grado de Bachiller en Filosofía y Letras, se organizaban en inferior y superior ${ }^{57}$; y técnica ${ }^{58}$, que otorgaba el grado de Bachiller en Ciencias, a la que se dio preferencia y con ello se abrió un mayor espacio para la enseñanza de las Ciencias naturales y las matemáticas ${ }^{59}$ en la educación colombiana, como lo establecen el Art. 11 de la Ley 39 de 1903 y el Art. 118 y 120 del Decreto 491 de 1904. Estos esfuerzos trataban de darle continuidad a las intenciones de la élite colombiana del siglo XIX por asegurar una formación técnica y científica que garantizara una orientación más práctica a la educación para sus hijos, que no se pudo alcanzar, porque la formación profesional y moral prevaleció.

Con estas nuevas propuestas para la instrucción en todos sus niveles, se le encomendó a las Escuelas Normales la formación de maestros idóneos para la enseñanza y educación de los niños en las Escuelas Primarias, formados como

54. Arts. 53, 54 y 55 del Decreto 491 de 1904.

55. Quienes debían "emplear todos los recursos de su inteligencia y de su corazón, a fin de hacer fácil a sus alumnos la práctica de los deberes para con Dios, para consigo mismo, para con sus padres y sus superiores, para con los semejantes y para con la patria", como parte de la educación moral de los alumnos, que predominó en la concepción de educación y limitó la formación científica y la respuesta a demandas de desarrollo económico o industrial.

56. Historia natural de tercero: monografías sacadas del reino animal, y conocimiento de las partes de que se compone el cuerpo humano; de cuarto: monografías sacadas de los reinos vegetal y mineral; de quinto: monografías un poco circunstanciadas de los animales de servicio, de los vegetales más necesarios y de los minerales más útiles (Art. 38, 41, Capítulo V, del Decreto 491 de 1904).

57 Para las siguientes materias: lenguas castellana, latina, francesa, inglesa; y Aritmética, seguida de Contabilidad; Algebra elemental; Geometría plana y del espacio; Geografía descriptiva, física y política de las cinco partes del mundo y especial de Colombia, y cosmografía elemental; Historia antigua y moderna y especial de Colombia; Física experimental; Retórica, Religión y Filosofía, en dos cursos (Art. 120 del Decreto 491 de 1904)

58. Esta instrucción técnica, "comprendía las nociones indispensables de cultura general, los idiomas vivos y las materias preparatorias para la Instrucción Profesional respectiva” (Art. 11 de la Ley 39 de 1903).

59. Los cursos que realizaban los alumnos con grado de bachiller en ciencias, indispensables para ingresar a la Facultad de Matemáticas, eran: "Religión, Gramática Castellana, Traducción de Inglés y Francés, Geografía Física, Aritmética, Álgebra, Geometría, Trigonometría Rectilínea, Física, Química General, Cosmografía, Lógica y Dibujo lineal” (Art. 118 del Decreto 491 de 1904). 
maestros prácticos, más pedagogos que eruditos ${ }^{60}$, como se decía en el Art. 15 de la Ley 39 de 1903.

Se entra a los años 20, con grandes debates nacionales en torno al problema educativo, que llevaron a esbozar, el papel de la Escuela Nueva, la introducción de las técnicas de la Psicología experimental y movilizaron a los intelectuales del país, como Agustín Nieto Caballero ${ }^{61}$; Germán Arciniegas decía que "no se hallaba atmósfera favorable a la investigación científica" con un "pensum que limita los estudios universitarios y paraliza la investigación"62; entre otros, que discutieron la política educativa del país y se preocuparon por la frágil formación de los maestros, que persistían en la aplicación de métodos autoritarios, con una orientación pedagógica que limitaba la formación científica y la respuesta a las demandas de desarrollo y con una enseñanza secundaria que era monopolio de las congregaciones religiosas, debido a la incapacidad del Estado para combatir la educación "verbalista" y el dogmatismo religioso, por medio de la propagación del conocimiento empírico y técnico.

Durante las primeras décadas del siglo XX, se identifican cambios en el saber pedagógico; en la educación pública, se complejiza y amplía la concepción sobre infancia y el saber biológico, y luego sociológico, que llevaron a acoger, en las prácticas pedagógicas, una pedagogía activa, tanto desde Decroly como Dewey, según lo afirman Zuluaga y Martínez Boom ${ }^{63}$.

60. Los maestros no sólo debían garantizar la adquisición de las nociones suficientes en el orden moral e intelectual, sino, también, en los principios fundamentales aplicables a la industria, a la agricultura y al comercio, para transmitirse a los niños, lo que no se cumplió. Se debe señalar que, en dicha formación de maestros, "la pedagogía teórica y práctica tenía un lugar importante en el horario escolar" (Helg, La educación en Colombia 1918-1957, 86), y entre las condiciones que debían cumplir los aspirantes a maestros no titulados, se exigía, además de la instrucción suficiente en las materias de primaria, "conocer la teoría de los métodos pedagógicos de la enseñanza primaria, y más especialmente su aplicación práctica" (Art. 75 de la Ley 39 de 1903). Según la citada Helg, dicha formación conducía a obtener el diploma de Maestro elemental, después de cuatro años de estudio; el título de Maestro superior se lograba con un año más de estudio y, para ser Maestro en un colegio o en la universidad se requerían, además, unos años de práctica. El programa contemplaba unas materias para la enseñanza primaria, otras de formación ideológica, como religión, moral e instrucción cívica e historia, geografía y ciencias naturales. A esta formación, más adelante, la criticó fuertemente Agustín Nieto Caballero, quien afirmaba: "la experiencia, aducida como criterio de convalidación del magisterio, era una aberración, un peso muerto, la cristalización del error, la pereza convertida en hábito" (Sobre el problema de la educación nacional (Bogotá: Ministerio de Educación Nacional, Ciencia y Cultura, 1937), 22).

61. Nieto Caballero propuso que las metodologías de enseñanza pusieran todo su esfuerzo para que la escuela estuviera al servicio de la vida, a través de modificaciones sustanciales en el aspecto pedagógico, que permitieran dejar atrás la pedagogía tradicional, la memorización y el dogmatismo, para avanzar hacia una nueva concepción del mundo, donde la experiencia personal, la libertad de expresión y el método experimental, entre otros, sirvieran para que a los maestros se los formara científicamente, como parte del sentido de la Escuela Nueva, según propuestas de pedagogos como María Montessori y Ovidio Decroly, quien expuso sus ideas en su visita al Gimnasio Moderno, en 1925.

62. Germán Arciniegas. Los Estudiantes y el Gobierno Universitario en La Reforma Universitaria, 1918-1930 (Caracas: Biblioteca Ayacucho, 1923-1925), 207-211.

63. Zuluaga y Martínez Boom, Historia de la educación y de la Pedagogía: desplazamientos y planteamientos. 
Otro acontecimiento significativo, para este estudio, que se registra en ese momento, fue la creación de la Escuela de Ciencias de la Educación, en 1926, en la Universidad de Antioquia, que representa la incursión de las Ciencias de la educación ${ }^{64}$. Desde esta perspectiva, se configuró una nueva práctica de saber y de poder para la formación de maestros y funcionarios de la educación pública, que trajo consigo el desplazamiento del saber pedagógico trabajado desde la pedagogía pestalozziana, por la pedagogía entendida como una de las Ciencias de la educación, en relación con las Ciencias sociales y naturales basadas en los métodos experimentales, según lo señala Ríos ${ }^{65}$. Se dio lugar a la desarticulación de la pedagogía y al desconocimiento de su capacidad para reconceptualizar. Se consideró, entonces, que "su campo de saber es disgregado y sus criterios de verdad son puestos en crisis por los desplazamientos y la multiplicación de sus objetos en las nuevas disciplinas de las ciencias de la educación", según lo señalan Zuluaga, Echeverry, Martínez, Restrepo y Quiceno ${ }^{66}$.

Surgen, entonces, reformas a la Ley Orgánica de Instrucción Pública, y una de ellas es la reforma reglamentaria de las Escuelas Normales en 1927, con la cual se organiza el primer curso de actualización para maestros normalistas en la Escuela Normal de Varones de Tunja, y se registra la llegada de la segunda Misión Alemana al país ${ }^{67}$, con la que, según Parra ${ }^{68}$, uno de sus aportes fue el "Curso Suplementario de Especialización", para maestros, en 1928, que sentó las bases para que, seis años más tarde, se crearan las Facultades de Ciencias de la Educación, masculinas, una en Bogotá, por Decreto 1990 de 1933, adscrita a la Universidad Nacional de Colombia, bajo la dirección de Rafael Bernal Jiménez, y otra en Tunja ${ }^{69}$. Así, se originó una nueva reflexión alrededor de la pedagogía y la educación colombianas, se creó la revista Educación, y la mayoría de profesores vinieron de Tunja con Bernal, quien había seguido los cursos de especialización de Sieber, donde se planteaba "la necesidad de formar los profesores para las

64. Según Ocampo y Bernal, las Ciencias de la Educación llegaron a Colombia por la vía de Suiza, relacionadas con las orientaciones del Instituto Juan Jacobo Rousseau, o Escuela de Ciencias de la Educación, fundado en 1912 por Claparéde y Bovet en la Universidad de Ginebra-Suiza. Javier Ocampo. Rafael Bernal Jiménez. Sus ideas educativas, sociológicas, humanistas y la Escuela Nueva en Boyacá (Bogotá: Plaza \& Janés, 2001).

65. Ríos,

66. Olga Lucía Zuluaga, et al. Educación y pedagogía una diferencia necesaria. En: Revista Educación y Cultura (14) (1988), 5.

68. Lina Adriana Parra.

69. Creada por Decreto 1379 de 5 de Julio de 1934, e 
Escuelas Normales, es decir, "los maestros de maestros", para la enseñanza secundaria, que hasta ese entonces no se formaban aún en el país, así como directores, supervisores y personal especializado ${ }^{70}$. Este es un indicio de la ausencia de formación pedagógica de los profesionales de otras áreas que se ocupaban de dicha enseñanza. Además, se creó la Facultad de Ciencias de la Educación ${ }^{71}$ para señoritas en Bogotá $^{72}$, donde sólo funcionaron las especializaciones de Pedagogía, Matemáticas y Ciencias Naturales, según Radke ${ }^{73}$.

Las corrientes pedagógicas que se aplicaron en las recién creadas Facultades de Ciencias de la Educación eran un tránsito entre la escuela tradicional y la Escuela Nueva ${ }^{74}$; como instituciones formadoras de maestros, permitieron una evolución histórica y un cambio estructural desde las Escuelas Normales, que más adelante se proyectarían como Universidades. De esta manera, las Facultades se constituyeron en un aporte al desarrollo intelectual de los nuevos ciudadanos, formados en la cultura científica y pedagógica, y para la mujer, que se proyectó en lo social y cultural gracias a las oportunidades de preparación profesional que se dieron en ese entonces, según lo señala Figueroa ${ }^{75}$.

Para 1934, en el marco de la Segunda Conferencia Nacional del Magisterio, donde se trataron temas como la organización de los maestros y la demanda de una "escuela primaria única, gratuita y obligatoria", se dio paso a un nuevo conflicto entre los defensores de la Iglesia y los que exigían la intervención del Estado en la educación. Estas demandas impulsaron los acontecimientos de un nuevo período en la educación colombiana ${ }^{76}$.

70. Helg,

y J. Ocampo.

1978), 34.

71. Con estos saberes, las Facultades de Ciencias de la Educación buscaban formar un maestro que reuniera a la vez la "ciencia y la técnica de su transmisión; no quiere una ciencia sin pedagogía, pero tampoco una pedagogía sin ciencia. Tampoco pretende formar diletantes sin profundidad en ningún campo del saber, ni profesores eruditos en un microscópico sector de la ciencia" (Reglamento Facultad Ciencias de la Educación (UPTC, 1934), 4).

72. Mediante Decreto 857, de abril 21 de 1934, del Ministerio de Educación, esta Facultad funcionó como parte de la Universidad Nacional y fue dependiente del Instituto Pedagógico Nacional de señoritas, fundado en 1927.

73. Francisca Radke. por Decreto 95 de 1934

74. Escuela Nueva afirmaba: el maestro debe ser el formador integral, el educador por excelencia, más que el instructor de contenidos, y se respaldaba en propuestas de pedagogos como María Montessori y Ovidio Decroly, quien expuso sus ideas en su visita al Gimnasio Moderno en 1925.

75. Claudia Figueroa.

76. Que se caracterizó por las aceleradas transformaciones que el presidente, Alfonso López Pumarejo (1934-1938) desencadenó con su programa Revolución en Marcha (Helg, La educación en Colombia 1918-1957). 
Un año más tarde, y en un contexto político de centralización y unificación de la formación de maestros y directivos de la educación pública, las tres Facultades de Ciencias de la Educación se fusionan en una sola institución, que se denominó: Escuela Normal Superior, con sede en Bogotá, que funcionó durante 15 años -1936-1951-, por Decreto 1917 de octubre de 1935, con la intención de poner la formación docente universitaria bajo la influencia directa del Estado, con un modelo europeo ${ }^{77}$.

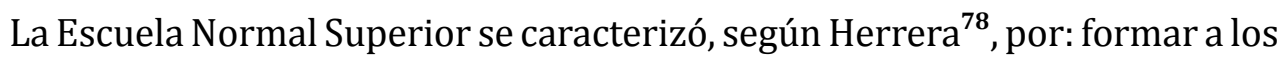
docentes tanto en lo científico como en la didáctica que promovía el aprendizaje de la ciencia a través de seminarios y de investigación; contar con profesores que se destacaban por ser intelectuales, muchos de ellos europeos que migraron en los años de los regímenes autoritarios; fundar institutos anexos de investigación que contribuyeron al fortalecimiento científico y la institucionalización de disciplinas en las áreas de las Ciencias Sociales y Humanas; privilegiar las Ciencias de la Educación más que la pedagogía, "como el espacio legítimo para reflexionar sobre el fenómeno educativo y sus diferentes dimensiones", tendencia que dio origen a la "fragmentación del objeto de la educación al ser tratado por varias disciplinas que atomizaron el saber de la pedagogía". Se manifiesta la tensión al fortalecer la formación científica y debilitar la pedagogía en la formación de maestros.

En Colombia desde 1946 se recrudece la lucha partidista por el poder y, con la llegada de los conservadores a la presidencia (1946-1953), se critica a la educación de la República Liberal; en este contexto, la Escuela Normal Superior

77. “El presidente López, considerando que para hacer más armónicos, serios y eficaces los altos estudios de las Ciencias Pedagógicas convenía reunir en una sola Facultad las tres que ya existían" (Martha Herrera y Carlos Low. Los intelectuales y el despertar cultural del siglo. El caso de la Escuela Normal Superior (Bogotá: Universidad pedagógica, 1994), 26). Tomó como modelo pedagógico la Escuela Normal Superior de París, creada para la formación de la intelectualidad francesa, la tradición alemana en las Facultades de Educación y la Educación Nueva impulsada por Agustín Nieto Caballero y Rafael Bernal Jiménez... (Edmundo Calvache. Las Facultades de Educación en Colombia durante el "Frente Nacional: 1958-1974. Balance y Prospectiva (Tunja: Universidad Pedagógica y Tecnológica de Colombia/RUDECOLOMBIA, 2006), 91). Esta influencia europea se sostuvo en la formación de maestros, en Colombia hasta 1950, según Rafael Flórez, Flor Alba Franco y Rocío Galvis (El saber pedagógico del profesor en Medellín. Medellín: Editorial Copiyepes, 1985). De igual forma, Renán Silva (La inmigración docente como posibilidad histórica: El caso de la Universidad Nacional de Colombia, 1930-1950. En: Revista Sociedad y Economía (15) (2008), 193) afirma que la "inmigración docente a la cultura moderna del siglo XX colombiano, tanto en el campo de las ciencias, como en el de las humanidades, fue de primer orden". La Escuela Normal Superior se constituyó en la única institución que hasta la primera mitad del siglo se encargó de la formación universitaria de los profesores, por tanto, fue una de las experiencias relevantes en la historia de la educación del País" (Martha Cecilia Herrera. La investigación educativa en la década del 80: Un esfuerzo cualitativo, 2000, p.108), que recogió los cambios generados en las Facultades de Educación, hacia la búsqueda de autonomía educativa en la Escuela Normal Superior de Bogotá, como Facultad Nacional de Educación, y se constituyó en el modelo institucional de educación superior en este periodo.

78. Herrera, La investigación educativa en la década del 80: Un esfuerzo cualitativo. 
entra en crisis ${ }^{79}$ y se cierra en 1952. Según Helg ${ }^{80}$, el periodo comprendido entre 1946 y 1957 fue decisivo en la configuración del sistema educativo colombiano, por los acontecimientos que se sucedieron en un contexto de transformaciones económicas, demográficas, políticas y de violencia. En lo que se refiere a la formación de maestros con título de Licenciado en Colombia, se consolida primero en la Universidad Nacional y luego en las dos universidades pedagógicas creadas ${ }^{\mathbf{8 1}}$ "como parte de un proceso de transformación del saber pedagógico en saber de naturaleza superior (científico-disciplinar) que da lugar al Sistema Nacional de Formación de Docentes en Colombia, tanto para las Escuelas Normales superiores como para las universidades pedagógicas" ${ }^{\mathbf{8 2}}$, según lo señala Ibarra ${ }^{\mathbf{8 3}}$. Así, en 1951 se graduó, en la Antigua Facultad de Ciencias de la Universidad Nacional de Colombia, el primer Licenciado en Matemáticas Superiores, mientras que la Universidad Pedagógica Nacional de Colombia le entregó al país sus primeros Licenciados en Matemáticas y Física en el año $1953^{84}$.

Durante el período de gobierno denominado "Frente Nacional" (1958-1974), las Facultades de Educación en Colombia, encargadas de la formación de maestros, acogieron las políticas educativas del Estado de esa época, así como las corrientes pedagógicas que pretendieron otorgar un carácter universal al pensamiento pedagógico de estas Facultades, tales como el conductismo, el psicologismo y la tecnología educativa en los procesos de formación, junto a una forma específica y concreta del estudio sistemático y comparativo con mayor peso en la formación en las disciplinas, según lo señala Calvache, lo que es indicio de la persistencia de tensión entre pedagogía y Ciencias naturales.

A partir de los años sesenta, en la Universidad Nacional se incrementa la formación de Licenciados en los distintos campos disciplinarios y en Colombia crece el número de "Facultades de Educación y de unidades encargadas de formar educadores en las diferentes instituciones de educación superior" ${ }^{\prime 25}$. Se dio

79. Fue objeto de hostilidades porque se la consideraba como peligroso foco de ideas izquierdistas, según Calvache, Las Facultades de Educación en Colombia durante el "Frente Nacional: 1958-1974. Balance y Prospectiva.

80. Helg,

81. Se crea la Universidad Pedagógica Nacional en el año 1954, por Decreto 547 del 23 de febrero, y la Universidad Pedagógica y Tecnológica de Tunja en el año 1953, creada por el Decreto 2655.

82. En ese entonces, las Facultades de Educación se constituyeron en un soporte pedagógico significativo para la formación de maestros en Colombia, lo que permitió "la evolución histórica y un cambio estructural desde las Escuelas Normales orientadoras de la educación y proyectadas a las Universidades Pedagógicas de Bogotá y Tunja en los años cincuenta (50) del Siglo XX" (Figueroa, Orígenes, formación y proyección de las Facultades de Educación en Colombia, 1930-1954, 217).

83. Oscar Armando Ibarra. El sistema nacional de formación de docentes: el ejercicio docente como profesión. En Sandra Sandoval (comp.) La formación de educadores en Colombia. Geografías e imaginarios. Tomo I (Bogotá: Universidad pedagógica Nacional, 2001), 78-79.

84. Calvache, Las Facultades de Educación en Colombia durante el "Frente Nacional: 1958-1974. Balance y Prospectiva, 176.

85. Ibarra, El sistema nacional de formación de docentes: el ejercicio docente como profesión, 79. 
impulso a los programas de Ciencias de la Educación, como parte de la llamada "modernización de las estructuras sociales," en la que intervinieron factores internacionales ${ }^{\mathbf{8 6}}$, "mientras que el Ministerio de Educación Nacional y las Facultades de Educación preparaban a los maestros y funcionarios de la educación en la nueva cultura de la dominación y domesticación"87.

Por su parte, Aristizábal et $a l^{88}$, manifiestan que, entre 1965 a 1975, se dio inicio a una nueva era de injerencia ${ }^{89}$ desde "el pensamiento norteamericano hegemónico de la educación como motor del desarrollo" ${ }^{\text {90 }}$. Desde estas premisas, en Colombia, se crean políticas educativas de orden gubernamental nacional, que determinaron una "racionalidad en el sistema educativo... que no escapó a un planeamiento sistemático y detallado, al punto de constituir un modelo de currículo en relación con la Tecnología Educativa, capaz de satisfacer las necesidades creadas por el pensamiento imperial"91, se interviene la formación de maestros a través de la reforma a las Normales, adoptada por Decreto 1955 de 1951, que introdujo la Tecnología Educativa en detrimento de la formación pedagógica, amparada en políticas educativas que tenían "como propósito que el hombre colombiano sea más, produzca más, tenga más, pertenezca y participe más activamente en la comunidad y en los esfuerzos y beneficios del desarrollo del país"92.

Las Facultades de Educación, formadoras de educadores, no escaparon a esta injerencia que, según Flórez y Franco ${ }^{93}$, acentuó la influencia norteamericana en la educación colombiana, como consecuencia geopolítica de la postguerra

86. “El Plan Básico” de Rudolph Atcon y la asesoría de la Universidad de California, organizan el planeamiento de la Educación Superior, lo que conduce a la reestructuración administrativa del Ministerio de Educación Nacional y a la creación de Institutos especializados y la fundación de los INEM (Flórez, Franco y Galvis. El saber pedagógico del profesor en Medellín). Se trajo a la Misión Alemana, en el año 1965, para institucionalizar la enseñanza instruccional (Humberto Quiceno. Movimiento Pedagógico, posición crítica y lugar de liberación (pp. 95-128). En Hernán Suárez y Abel Rodríguez (comps.). 20 años, 1982-2002, del movimiento pedagógico: entre mitos y realidades (Bogotá: Cooperativa Editorial Magisterio/Corporación Tercer Milenio 2002), 102).

87. Quiceno, , 102.

88. Proyecto de investigación titulado "El campo curricular en la tradición educativa colombiana: 1960-1975", realizado por el Grupo de investigación Pedagogía y Currículo de la Universidad del Cauca (Aristizábal, 8), con informe, que se encuentra en el libro: Traslapamiento de la pedagogía por el currículo: Colombia 1960-1975 (Popayán: Universidad del Cauca/RUDECOLOMBIA).

89. Fundaciones, como la Ford, Kellogg, Rockefeller, y otros organismos, como la Agencia Interamericana de Desarrollo (AID), el Banco Interamericano de Desarrollo (BID), el Banco Mundial, la ONU, la OEA, intervinieron en el diseño e implementación de políticas educativas en Colombia. Se crearon Institutos descentralizados del Estado (ICETEX, Instituto de Investigaciones Tecnológicas, ICA, SENA, INCORA, Instituto de Asuntos Nucleares, entre otros) (Colciencias/DNP, 2019 Visión Colombia II Centenario. Fundamentar el crecimiento y el desarrollo social en la ciencia la tecnología y la innovación, 2006, 5).

90. Aristizábal, Traslapamiento de la pedagogía por el currículo: Colombia 1960-1975, 48.

91. Aristizábal, Traslapamiento de la pedagogía por el currículo: Colombia 1960-1975, 48.

92. Aristizábal, Traslapamiento de la pedagogía por el currículo: Colombia 1960-1975, 61.

93. Flórez, Franco y Galvis, 
mundial, a través de créditos y financiación a las universidades, con miras a la implantación del currículo y el nuevo modelo pedagógico conductista de Tecnología Educativa ${ }^{\mathbf{9 4}}$, con una clara tendencia pragmatista en la formación de Licenciados, desde teorías funcionalistas de la educación, que ocasionaron un desplazamiento de la pedagogía, tanto de los programas de formación como de las prácticas pedagógicas de los maestros, según Rodríguez ${ }^{95}$. Desde ese entonces, a la formación de maestros en Colombia la atraviesan lo curricular y la planeación que, según Aristizábal ${ }^{96}$, se constituye en una "forma de colonizar nuestro pensamiento indoamericano, permitiendo y estimulando la adopción en la vida educativa colombiana de una racionalidad tecnocrática que ya tenía desde el siglo XIX la impronta del llamado "progreso" y la "civilización".

De esta manera, "fueron precisamente el currículo y la administración, los discursos que excluyeron la pedagogía del seno de las Universidades, Facultades de Educación, escuelas y de las investigaciones educativas" ${ }^{\prime 97}$. Esta es otra manifestación más de la tensión disciplinar en estudio. A este nuevo orden, que muestra una clara intención de despedagogizar la formación de educadores en Colombia, se sumaron las consecuencias adversas, en la educación, que trajeron las políticas de autofinanciación y la reducción de partidas estatales, dando lugar a la privatización y crisis en la educación pública, según Herrera ${ }^{\mathbf{9 8}}$.

Según Ocampo ${ }^{99}$, se pueden identificar cuatro tendencias vinculadas al proceso de constitución de las Universidades Pedagógicas en Colombia y a la formación de maestros, que se mueven en diferentes direcciones y hacen evidente el estado de la tensión disciplinar entre pedagogía y ciencias en la formación de Licenciados, con diferente intensidad, según el lugar y peso que se otorga a la formación pedagógica y a la formación científica, como se describe en el Cuadro 1.

94. Por Decreto 1964 de 1969, se autoriza a las universidades para estructurar programas de formación con destino a la docencia, la administración escolar y los servicios educativos (Abel Rodríguez.

16).

"Las cuatro estrategias" (1970-74), "Para cerrar la brecha” (1975-78), "Plan de integración nacional” (1979-82) y “Cambio con equidad” (1982-86), que le reconocen explícitamente algún papel a la educación y a la formación de los recursos humanos frente al desarrollo del país, según Flórez, Franco y Galvis, , 15.

95. Rodríguez, El Movimiento Pedagógico un encuentro de los maestros con la pedagogía, 16.

96. Aristizábal, Traslapamiento de la pedagogía por el currículo: Colombia 1960-1975, 10.

97. Quiceno,

98. Herrera,

99. Javier Ocampo.

1998. 


\section{Cuadro 1. Tensión en las tendencias de formación de maestros en Colombia}

\begin{tabular}{|c|c|c|c|}
\hline Tendencia & Caso & Periodo & Tensión \\
\hline $\begin{array}{l}\text { Formación pedagógica y } \\
\text { científica en el mismo nivel } \\
\text { y profundidad. }\end{array}$ & $\begin{array}{l}\text { Cursos Suplementarios y de las Facul- } \\
\text { tades de Educación }\end{array}$ & $\begin{array}{l}\text { Década de } \\
\text { los treinta }\end{array}$ & $\begin{array}{l}\text { Menos in- } \\
\text { tensidad }\end{array}$ \\
\hline $\begin{array}{l}\text { Prima la ciencia con el más } \\
\text { alto rigor científico y a su alre- } \\
\text { dedor la pedagogía. }\end{array}$ & Escuela Normal Superior de Colombia & $\begin{array}{l}\text { Década de } \\
\text { los cuarenta }\end{array}$ & $\begin{array}{l}\text { Mayor in- } \\
\text { tensidad }\end{array}$ \\
\hline $\begin{array}{l}\text { Prima la formación pedagógi- } \\
\text { ca y a su alrededor la forma- } \\
\text { ción científica. }\end{array}$ & $\begin{array}{l}\text { Universidades pedagógicas, de carác- } \\
\text { ter profesional pedagógico. Universi- } \\
\text { dades Pedagógicas en Tunja y Bogotá. }\end{array}$ & $\begin{array}{l}\text { Década del } \\
\text { cincuenta y } \\
\text { sesenta. }\end{array}$ & $\begin{array}{l}\text { Mayor in- } \\
\text { tensidad }\end{array}$ \\
\hline $\begin{array}{l}\text { Muchos contenidos científi- } \\
\text { cos y lo pedagógico como un } \\
\text { barniz complementario para } \\
\text { la actividad docente. }\end{array}$ & $\begin{array}{l}\text { Universidades multiprofesionales, en } \\
\text { las cuales se da especial importancia } \\
\text { a las Ciencias naturales y humanas y } \\
\text { unos cursos pedagógicos, que popu- } \\
\text { larmente se denominan "cachucha } \\
\text { pedagógica" para la formación de los } \\
\text { docentes. }\end{array}$ & $\begin{array}{lr}\text { Década } & \text { del } \\
\text { setenta } & \text { y } \\
\text { ochenta }\end{array}$ & $\begin{array}{l}\text { Crisis a la } \\
\text { formación }\end{array}$ \\
\hline
\end{tabular}

Fuente: Javier Ocampo (1998, 195-196), adaptada para esta investigación

En este contexto, el magisterio colombiano se organiza, en 1969, en la Federación Colombiana de Educadores (FECODE), que congregó inicialmente a los profesores de enseñanza primaria y, después, pasó a representar a los docentes de todos los grados de enseñanza que, entre 1975 y 1980, junto a algunos investigadores y profesores universitarios, del centro y las distintas regiones del país, dan vida al Movimiento Pedagógico ${ }^{\mathbf{1 0 0}}$, cuyo objetivo fue establecer un pensamiento pedagógico a partir del cual organizar la educación ${ }^{\mathbf{1 0 1}}$.

Por su parte, en la década del 80, el Estado colombiano le imprime mayor fuerza a la reforma educativa y curricular ${ }^{102}$; además, se promulga el Decreto Ley

100. Los propósitos que persiguió el Movimiento Pedagógico fueron: adelantar una reflexión colectiva sobre la identidad y el papel cultural del educador; aglutinar y elaborar las preocupaciones profesionales del magisterio y sus esfuerzos aislados, hacer más vigorosa la búsqueda de alternativas pedagógicas; incidir en el cambio educativo desde el saber pedagógico y la presión sindical; luchar por mejores condiciones para los maestros; contribuir a fundamentar y orientar transformaciones en la formación y actualización de los maestros (CEID-FECODE, 1985). que se constituye en un Movimiento, sin precedentes en la historia de la pedagogía latinoamericana, por ser un encuentro de los maestros con su saber, que es la pedagogía (Rodríguez, El Movimiento Pedagógico un encuentro de los maestros con la pedagogía), que retoma ciertos elementos del pasado histórico más inmediato, con el interés de rescatar la pedagogía activa, la pedagogía universal, su historia y los grandes pedagogos. Así como "para liberar la educación, el maestro y la escuela, de los modelos industriales (administrativos y curriculares) basados en el concepto de sistema y en la norma" (Quiceno, Movimiento Pedagógico, posición crítica y lugar de liberación, 105-121).

101. Quiceno, Movimiento Pedagógico, posición crítica y lugar de liberación. 
080 de 1980, que establece el título de Licenciado como identificación exclusiva de los profesionales de la educación, complementado con la ciencia o ciencias que serán objeto de su ejercicio profesional: Licenciado en Física; Licenciado en Biología y Química; de esta manera, se suprimió la denominación "Ciencias de la Educación" en las titulaciones. No obstante, en los años ochenta, en Colombia, la investigación en educación empieza a legitimar su campo intelectual, al abrirse espacios públicos de carácter académico, institucionales, gubernamentales y sindicales, según Henao y Castro ${ }^{\mathbf{1 0 3}}$. Así, transcurre esta década, que se caracteriza por las posiciones divergentes que asumen los maestros desde el Movimiento Pedagógico y el Estado colombiano con la inclusión de políticas lesivas para la educación.

La década del 90, en Colombia, se caracteriza por la clara intención de cambio a partir de la Constitución Política de $1991^{104}$, la Ley 30 de 1992 de Educación Superior, que sugiere la organización de las universidades del Estado como un sistema y reconoce la autoevaluación como parte constitutiva del proceso de acreditación voluntaria hacia una cultura para alcanzar la calidad, ideas que se complementan desde la Misión de Ciencia, Educación y Desarrollo de 1994 y la promulgación de la Ley General de Educación 115 de 1994, en la que se reconoce a la pedagogía como el saber fundante en la formación y la práctica de los educadores y se define una nueva concepción sobre educación ${ }^{105}$. No obstante, persiste el desconocimiento de la necesidad de modificar los objetivos, contenidos y estrategias de enseñanza de las ciencias, para atender a dicha concepción.

Posteriormente, se instaura el Registro calificado ${ }^{106}$ para todos los programas de Educación Superior, con vigencia hasta la actualidad. De igual forma, se elaboran unos Lineamientos curriculares para la Educación Básica y Media, en que se identifican áreas obligatorias y fundamentales (nueve), entre las cuales aparece el área de Ciencias Naturales y Educación Ambiental, y se exige que "cada programa de formación inicial de profesores (Licenciatura), debía ser formulado y puesto en práctica de conformidad con el nivel para el cual se preparaba al docente", con estas disposiciones, y "todos los resultados de las investigaciones en didáctica de las ciencias experimentales fueron echados a un lado o, por

103. Myriam

104. La Constitución Política Colombiana de 1991, en su Artículo 67, establece que la educación es un derecho de la persona y un servicio público, que tiene una función social y de calidad.

105. Expresa: "La educación es un proceso de formación permanente, personal, cultural y social que se fundamenta en una concepción integral de la persona humana, de su dignidad, de sus derechos y de sus deberes", y que es deber del Estado atender en forma permanente los factores que favorecen la calidad y el mejoramiento de la educación.

106. El Registro calificado es el instrumento del Sistema de Aseguramiento de la Calidad de la Educación Superior, mediante el cual el Estado verifica el cumplimiento de las condiciones de calidad por parte de las instituciones de Educación Superior, según lo establece la Ley 1188 de 2008. 
ignorancia, no se incorporaron en la mayoría de los casos a estos programas de Licenciatura", como lo manifiesta Gallego ${ }^{107}$.

Desde este marco, se definen los criterios para orientar los programas de formación de educadores y a las Facultades de Educación se le ha asignado la misión de fortalecer la investigación pedagógica, formar científicos y expertos en educación con identidad ética y pedagógica ${ }^{\mathbf{1 0 8}}$ para: asesorar en planes y programas educativos de la sociedad; la pedagogía universitaria y la investigación e innovación para formular políticas y legislación oficial en materia de educación, entre otros, según lo señala Dueri ${ }^{109}$. Así, se puede documentar que "la noción de maestro y/o docente investigador ${ }^{\mathbf{1 1 0}}$, incursiona en las Facultades de Educación y en las Escuelas Normales Superiores a través de los discursos producidos por los grupos de investigación, las políticas y reformas educativas que buscan darle su soporte"111.

Con todas estas manifestaciones de reconocimiento, optimismo y nuevos retos para la formación de educadores en Colombia, se esperaba que, al entrar al nuevo siglo, estas ideas prometedoras se consolidaran para alcanzar un mayor avance en el reconocimiento del maestro como individuo en interacción social, que produce saber pedagógico, desde la investigación, situación que no ha tenido lugar y, por el contrario, como afirma Mejía ${ }^{112}$, "el nuevo milenio nos sorprende con una serie de contra reformas educativas, en donde se echan atrás algunos de los elementos más progresistas de las Leyes de educación, el conocimiento se reduce a estándares y competencias..."113, la pedagogía se invisibiliza para convertirse en una función técnica y complementaria del hecho educativo, siendo así una nueva manifestación de la tensión en estudio.

107. Rómulo

108. Esta década se caracterizó por un optimismo educativo cimentado sobre tres hechos: las necesidades de la globalización centradas en el conocimiento, la modernización de los aparatos educativos para dar respuesta a los cambiantes tiempos, y la profesionalización docente, que anunciaba la mayoría de edad de la pedagogía, según Marco Raúl Mejía (Leyendo las políticas educativas de la globalización, 3).

109. Elba Martínez de

110. Aparece la demanda del maestro investigador y, para ello, se retoman y generan programas que lo involucran en esta actividad, todos ellos respaldados por la preocupación de mejorar la calidad de los procesos educativos, idea compartida por el Movimiento Pedagógico en la década del 80 ... (Raúl Ortiz y Juan Pablo Suárez. La formación de maestros y la noción de maestro investigador (1996-2005). Un 111. espacio para la reflexión y el debate (Medellín, Universidad de Antioquia, 2009), 66).

112. Marco Raúl

113. "Las reformas se reducen a unos criterios de costo-beneficio, con políticas de capitalización (pago por alumno atendido) en donde el menor costo financiero desplaza al proyecto pedagógico. La propuesta curricular en competencias termina siendo un retorno al maestro a prueba de currículo que diseñó la tecnología educativa taylorizada de los setenta, sólo que con los retoques del toyotismo" (Mejía, Leyendo las políticas educativas de la globalización). 
En esta forma, irrumpe la Ley 715 de 2001, para reacomodar lo establecido en la Ley General de Educación 115, y desvirtúa su sentido, en relación con la autonomía del maestro, con la justificación de garantizar la educación para todos, de calidad, desde normas técnicas curriculares y pedagógicas para todos los niveles de educación, expresadas en los estándares básicos en competencias ${ }^{\mathbf{1 1 4}}$. No obstante, se puede destacar que algunos maestros, instituciones de formación e investigadores, continuaron trabajando en dirección al cambio educativo, como protagonistas en la construcción del saber pedagógico, la educación en ciencias y el avance de la ciencia en Colombia, como se puede identificar en las siguientes experiencias y hechos importantes, desde 1980 hasta la actualidad:

1. La conformación de Grupos, Redes y Asociaciones, que persisten en construir, fundar y consolidar investigación educativa en ciencias, como se referencia a continuación:

Los grupos de investigación se fortalecen y aportan una masa crítica muy importante para la educación, la pedagogía y la formación del maestro en ciencias, entre los que se destaca el Grupo Historia de las Prácticas Pedagógicas ${ }^{\mathbf{1 1 5}}$. Por su parte, el grupo del profesor Carlo Federici ${ }^{\mathbf{1 1 6}}$, de la Universidad Nacional, realizó grandes esfuerzos "por vincular la cultura pedagógica colombiana a los horizontes conceptuales de las ciencias naturales y humanas". Es importante destacar que "con este grupo se inician discusiones alrededor de la educación en las ciencias y en las matemáticas, se participa activamente en el Movimiento Pedagógico"117.

Se conforman Redes de maestros apoyadas por algunas universidades, como es el caso de la Universidad Pedagógica Nacional, con sus programas de Expe-

114. Documento que elabora el Ministerio de Educación Nacional en el año 2003. Además, “centra la atención en la regulación de la calidad de la educación desde la evaluación permanente, el mejoramiento continuo y los resultados del aprendizaje, todo ello orientado a la optimización del servicio educativo" (Ortiz y Suárez. La formación de maestros y la noción de maestro investigador (1996-2005), 69-70).

115. Las raíces del grupo se encuentran en el proyecto Filosofía y Pedagogía, organizado por Olga Lucía Zuluaga en la Facultad de Educación de la Universidad de Antioquia (1975-1978), que, a su vez, impulsa el proyecto universitario: "Hacia una Historia de la Práctica Pedagógica en Colombia”, desde una perspectiva orientada a desentrañar las condiciones sociales de existencia de la pedagogía en Colombia, su especificidad como saber y como práctica, que comenzó a consolidarse, como una corriente de investigación pedagógica pionera, no sólo en el ámbito pedagógico colombiano, sino también en el latinoamericano.

116. Carlo Federici Casa, estudioso de las ciencias básicas y naturales, con vocación de maestro de ciudadanos tolerantes, honestos y respetuosos, revolucionó la pedagogía nacional en la década de los 80, organizó varios seminarios en la Facultad de Ciencias Humanas de la Nacional para discutir temas relacionados con pedagogía. Dirigió, en la Universidad Nacional de Colombia, el Departamento de Ciencias de la Educación (1972) y, luego, el Departamento de Pedagogía de la Facultad de Ciencias Humanas (1975); desde allí, convocó a un seminario sobre teoría del conocimiento a profesores de distintas Facultades, que más adelante conformarían, bajo su orientación, el llamado Grupo Federici (José Granés y Luz Marina Caicedo, En este saber he creído, de este saber he vivido: Escritos del profesor Carlo Federici Casa sobre Ciencia Matemática y Docencia, 2002).

117. Granés y Caicedo, , 1-7. 
dición Pedagógica, donde convergen la Red CEE y la Red de la Universidad Nacional; además, surgen las Redes de maestros de lenguaje, matemática, Ciencias naturales y Ciencias sociales, organizadas para construir, analizar, reflexionar e investigar pensamiento educativo en el país. Según Henao y Castro ${ }^{\mathbf{1 1 8}}$, los productos de la investigación, de los diferentes grupos y Redes, en el campo de la investigación educativa y pedagógica, empiezan a reconocerse como fuente de comprensión de problemas, identificación de obstáculos, reconocimiento de actores, circulación de publicaciones y de inspiración de políticas gubernamentales en educación.

Se registra el trabajo sistemático y significativo de la Academia Colombiana de Ciencias Exactas, Físicas y Naturales, que se remonta a 1933 cuando, mediante la Ley 34, se crea como organismo consultor del Gobierno Nacional en asuntos relacionados con la Ciencia ${ }^{119}$; dedicada al impulso de la educación en ciencias en Colombia, con una actividad intensa que se traduce en aportes al mejoramiento permanente de la enseñanza de las ciencias en los diferentes niveles de la educación y al fomento y desarrollo del conocimiento científico y la investigación en los campos de las Ciencias, como se registra en su informe de actividades 2009-2010.

De otro lado, el trabajo de la Asociación Colombiana para el Avance de la Ciencia (ACAC), creada en 1970, como un organismo representante de la comunidad científica que se ocupa del fomento y la coordinación de actividades científicas y tecnológicas a nombre de dicha comunidad, en diferentes sectores de la sociedad, como el académico, el empresarial, el artístico y el juvenil.

A estos esfuerzos se suma, la preocupación por el desarrollo investigativo en las áreas de la educación, la pedagogía y la didáctica de las ciencias y la tecnología en Colombia, que lleva a un grupo de docentes investigadores de diferentes universidades ${ }^{\mathbf{1 2 0}}$ a fundar la Asociación de investigadores de Educación en Ciencias y Tecnología (EDUCYT), que cuenta con un medio de difusión masiva, como es la revista electrónica, realiza Congresos que buscan ser el punto de encuentro, indispensable para afianzar comunidades críticas científicas y educativas, conformadas por educadores en ciencias del país, investigadores de sus propias prácticas y protagonistas de su mejoramiento para abrir nuevos

118. Henao y Castro,

119.

120. Quienes la hicieron posible, como miembros de su primera junta directiva, elegida en la Asamblea Fundacional que se realizó en la ciudad de Ibagué, gracias a la generosa hospitalidad de la Universidad del Tolima: los profesores y profesoras Adela Molina, su primera presidenta; Fanny Angulo, Alfonso Claret Zambrano, Miguel Corchuelo, Julio Enrique Duarte, Carmen Alicia Martínez, Aníbal Mendoza, Rosa Inés Pedreros, Oscar Eugenio Tamayo, Carlos Uribe y Diego Villada. 
caminos y oportunidades en este oficio de enseñar, aprender, evaluar e investigar en educación en ciencias y tecnología, como se expresa en la Reseña Histórica EDUCYT, de $2009^{121}$.

2. La publicación de revistas "con el propósito de formar una masa crítica de investigadores en la enseñanza de las ciencias en 1981", año en el que se inició la publicación de la revista Naturaleza-Educación y Ciencia. El campo de la educación y la investigación en ciencias lo retomó el profesor Dino Segura, en 1995, quien, con su Boletín Nemqueteba, trató de responder a la urgencia de consolidar la comunidad de educadores en ciencias, innovadores e investigadores ${ }^{\mathbf{1 2 2}}$. No obstante los múltiples tropiezos, se puede hoy mencionar que se cuenta con un número significativo de publicaciones periódicas.

3. La consolidación de la institucionalidad de la CT+I en Colombia, a través de las siguientes etapas y eventos: una primera etapa, entre 1968 y 1989, en la que se destaca la creación de COLCIENCIAS y el Consejo Nacional de Ciencia y Tecnología y la primera Misión de Ciencia y Tecnología (1988); la segunda etapa, entre 1990 y 1999, cuando se resalta la Promulgación de la Ley 29 de 1990: Definición de la Política Nacional de Ciencia y Tecnología, la segunda Misión de Ciencia, Educación y Desarrollo (1993) y la creación del Observatorio Colombiano de Ciencia y Tecnología (1999). El estudio sobre el estado del arte de la enseñanza de las ciencias en Colombia, 1990-1999 ${ }^{\mathbf{1 2 3}}$, que si bien permite esbozar algunas líneas de investigación de la formación en ciencias, también "muestra un gran vacío, [pues] el trabajo al interior del aula es prácticamente ignorado. La enseñanza de las ciencias, su aprendizaje y su evaluación son poco relevantes en este periodo"124. Finalmente, se promulga la Ley 1286 de 2009, con la que se alcanza una etapa culminante en la institucionalización del Sistema Nacional de Ciencia, Tecnología e Innovación en Colombia, al reglamentar la CT+I que transforma a COLCIENCIAS en Departamento Administrativo de Ciencia, Tecnología e Innovación y crea el Sistema Nacional de Ciencia, Tecnología e Innovación (SNCTI), refuerza la institucionalidad para identificar, transferir, producir y proveer los conocimientos que el bienestar de las personas y el desarrollo del país y sus regiones requieren ${ }^{125}$.

121. Este documento es una versión abreviada y editada de la presentación de la Asociación, realizada por el profesor Alfonso Claret Zambrano, de la Universidad del Valle, en la Asamblea Fundacional de la entidad (Universidad del Tolima, Ibagué, 30 de agosto de 2004).

122. Zambrano, 2009, 3.

123. Realizado por Carlos Augusto Hernández (2001) en el marco del estudio: Estado del arte sobre investigación educativa y pedagógica en Colombia: balance de una década con la orientación de los grandes fines que atañen directamente a la formación en ciencias y con base en los proyectos de investigación presentados a Colciencias.

124. Zambrano, 2009, 9.

125. Zambrano, 2009, 1-10. 


\section{CONCLUSIONES}

En Colombia, la tensión estudiada persiste en la formación de los educadores en ciencias, con diferentes matices a lo largo de la Historia, y se presenta asociada a las formas de pensamiento que conciben tanto a la pedagogía como a las Ciencias naturales desde diferentes posturas teóricas, intereses prácticos, políticos y sociales, que orientan la educación y establecen relaciones de poder, por lo que este recorrido muestra la preocupación y avances que se pueden destacar en la historia de la formación en ciencias en Colombia, que se relaciona simultáneamente con avances, con dificultades, limitaciones y anhelos pendientes, que forman parte de un proceso que inicia su trayecto en el siglo XVIII, con la influencia del pensamiento ilustrado, la llegada de Mutis a la Nueva Granada, que despierta el interés por el conocimiento científico, la formación de maestros idóneos desde la relación maestro/discípulo y el Plan Moreno y Escandón, que propuso un método desde el eclecticismo para orientar la educación hacia una concepción más práctica y hacia las ciencias experimentales.

Después, la consolidación del nuevo Estado independiente exigía la formación pedagógica y científica de maestros para la instrucción pública del nuevo ciudadano, que debía asistir a las recién creadas escuelas para la enseñanza mutua, en las primeras ciudades, que demandaban una nueva relación de comunicación y divulgación del conocimiento, que obligaba a dejar la relación maestro/discípulo e incluir el método en la formación de maestros. Posteriormente, se orientó la educación "hacia lo práctico y lo útil", apoyada en la libertad de enseñanza, la prevalencia de conocimientos industriales, las ciencias exactas y naturales, para garantizar la formación de ciudadanos en profesiones prácticas, lo que evidencia cómo la pedagogía quedó relegada a un segundo plano.

Con la aprobación de la Constitución de Rionegro, en 1863, se da paso a uno de los períodos de reforma educativa de gran importancia en la historia del siglo XIX, en todos sus niveles, al reconocer las libertades individuales de expresión, pensamiento, enseñanza, culto, entre otras, desde una concepción de sistema, de enseñanza e instrucción pública, obligatoria y gratuita, entendida como una función del Estado, orientada a la libertad, a formar maestros idóneos en los métodos de enseñanza de Pestalozzi, para dirigir las Escuelas Normales, que se crearon, en cada capital de Estado, con criterios pedagógicos y científicos, según el Decreto Orgánico de Instrucción Pública (DOIP, 1870, Art. 62), que dejaba entrever la intención por recuperar el valor de la pedagogía en la formación de maestros, junto a las ciencias. Estas reformas se sostuvieron hasta 1886, cuando una nueva Constitución reorientó drásticamente el sistema educativo colombiano, al establecer la no obligatoriedad de la educación pública gratuita, 
organizada y dirigida según los dogmas y la moral de la Religión Católica, a lo cual se agregan las limitaciones presupuestales y las guerras civiles, que truncan las intenciones para la educación y la formación de maestros.

Durante la primera mitad del siglo XX, se reorganizó la educación en el país con un sentido más pragmático y adecuado a los nuevos desarrollos de la economía, según la Ley Orgánica de Instrucción Pública de 1903, que promovía una educación intelectual, donde primero se esperaba formar maestros idóneos y prácticos, más pedagogos que eruditos y, después, con la renovada concepción sobre infancia, el saber biológico y sociológico, se orientó dicha formación hacia una pedagogía activa y a la creación de las Facultades de Ciencias de la Educación, que configuraron una nueva práctica de saber y de poder para la formación de maestros y funcionarios de la educación pública, lo que trajo consigo el desplazamiento del saber pedagógico, trabajado desde la pedagogía pestalozziana, por la pedagogía entendida como una de las Ciencias de la educación y nuevamente se identificó la necesidad de formar profesores para enseñar en las Escuelas Normales y para la enseñanza secundaria.

En 1936, se fusionan las tres principales Facultades de Ciencias de la Educación, en una sola institución, que se denominó: Escuela Normal Superior, con sede en Bogotá, que funcionó hasta 1951, donde se atomizó el saber de la pedagogía al privilegiar las Ciencias de la Educación, promover el fortalecimiento científico, como una manifestación más de la tensión en estudio, que debilita a la pedagogía en la formación de maestros.

En los años cincuenta, al cerrarse la Escuela Normal Superior, se hace un cambio estructural que dio lugar a la creación de las Universidades Pedagógicas de Bogotá y Tunja, donde se formaron los primeros maestros con título de Licenciado en Colombia, desde corrientes pedagógicas tales como: el conductismo, el psicologismo y la tecnología educativa y las ciencias de la educación, que desplazan a la pedagogía y la instrumentalizan. También se registra, en los años sesenta, un incremento en el número de Facultades de Educación para preparar maestros desde una nueva cultura de la dominación, domesticación y la injerencia norteamericana en la educación colombiana; esta vez fueron el currículo, la administración y la planeación, los discursos que excluyeron a la pedagogía del seno de las Universidades, los que son indicios de la tensión que persiste en el desplazamiento de la pedagogía, tanto de los programas de formación como de las prácticas pedagógicas de los maestros.

No obstante, en los años ochenta, en Colombia, la investigación en educación empieza a legitimar su campo intelectual, al abrirse espacios públicos de carácter académico, institucionales, gubernamentales y sindicales, que surgen 
en oposición a estas tendencias, como es el caso del Movimiento Pedagógico, que buscaba establecer un pensamiento pedagógico para organizar a la educación, lo que, en parte, se alcanza en la década del 90, en la Constitución Política de 1991 y la Ley 30 de 1992 de Educación Superior, que definen una nueva concepción sobre educación y donde se reconoce a la pedagogía como el saber fundante en la formación y la práctica de los educadores. Aunque esta normativa sigue vigente, el nuevo milenio trae contrarreformas que debilitan sus elementos más progresistas, al reducir el conocimiento a estándares y a competencias; en lugar de producir saber pedagógico, desde la investigación, se subvalora a la pedagogía al asignarle una función técnica y complementaria del hecho educativo, lo que es una nueva manifestación de la tensión en estudio.

La ciencia deja de ser un fenómeno intemporal, hegemónico, y pasa a convertirse en un quehacer ontológico, producto de un esfuerzo colectivo, inacabado e inacabable, en el que cada generación tiene algo que añadir.

La pedagogía se ha debatido entre la posibilidad de constituirse en un saber autónomo (fundante del ser y quehacer del maestro, que se relaciona interdisciplinariamente con otras ciencias) y la opción que la relega a un segundo plano frente a los problemas educativos en ciencias, que desconoce su status de saber, producido por los maestros investigadores.

Finalmente, se reconoce que, en los últimos treinta años, "el desarrollo de la investigación y la innovación en educación en ciencias, ha sido vertiginoso"126; se ha producido nuevo conocimiento pedagógico y cambios en la formación de Licenciados que emprenden nuevas formas de enseñar y aprender las Ciencias Naturales. 


\section{REFERENCIAS BIBLIOGRÁFICAS}

Arboleda, Luis Carlos. Matemáticas, Cultura y Sociedad en Colombia. Historia Social de la Ciencia en Colombia. Tomo II, primera parte, pp. 15-172. Bogotá: COLCIENCIAS, 1993.

Arciniegas, Germán. Los Estudiantes y el Gobierno Universitario en La Reforma Universitaria, 1918-1930. Caracas, Biblioteca Ayacucho, 1923-1925.

Aristizábal, Magnolia; María Eugenia Muñoz y Carlos Tosse. El gigante en el país de los liliputienses: Las ilusiones del desarrollo y el planeamiento para la educación (pp.48-86) En: Magnolia Arsitizábal (comp.). Traslapamiento de la pedagogía por el currículo: Colombia 1960-1975: Voces y miradas sobre el paradigma anglosajón en educación. Popayán, Colombia: Editorial Universidad del Cauca, 2008.

Báez, Miryam. La formación de maestros en Colombia y Argentina entre 1870 -1880. En: Revista Historia de la Educación Colombiana (3, 2,) (2001): 87-104.

Barrios Ana. La tensión disciplinar entre pedagogía y Ciencias naturales en la formación de Licenciados: Universidad de Nariño. Popayán: Universidad del Cauca/Rudecolombia, 2014 (Tesis doctoral).

Calvache, Edmundo. Las Facultades de Educación en Colombia durante el "Frente Nacional": 1958-1974. Balance y Prospectiva. Tunja: Universidad Pedagógica y Tecnológica de Colombia/Rudecolombia, 2006 (Tesis doctoral).

Concordato entre la Santa Sede y la República de Colombia, 31 de diciembre de 1887. En: Conferencias Episcopales de Colombia. Tomo I (1908-1935). Bogotá, 1956.

Departamento Administrativo de Ciencia, Tecnología e Innovación (COLCIENCIAS) \& Departamento Nacional de Planeación (DNP). 2019 Visión Colombia II Centenario. Fundamentar el crecimiento y el desarrollo social en la ciencia la tecnología y la innovación. Bogotá: DNP, 2006.

Díaz, Santiago. La ilustración en la Nueva Granada: su influencia en la educación y en el movimiento de emancipación. El caso de Mutis. En: Boletín de Historia y Antigüedades, 92 (828) (2005): 117-128.

Figueroa, Claudia. Orígenes, formación y proyección de las Facultades de Educación en Colombia, 1930-1954. En: Revista Rhela (8) (2006): 199-218.

Flórez, Rafael; Flor Alba Franco y Rocío Galvis. El saber pedagógico del profesor en Medellín. Medellín: Editorial Copiyepes, 1985.

Gallego, Rómulo; Royman Pérez y Luz Nery Torres. La formación inicial de profesores de ciencias en Colombia. Bogotá: Universidad Pedagógica Nacional, 2005.

García, Bárbara. La educación Colonial en la Nueva Granada: entre lo doméstico y lo público. En: Revista Rhela (7) (2005): 217-238

Granés, José y Luz Marina Caicedo. En este saber he creído, de este saber he vivido: Escritos del profesor Carlo Federici Casa sobre Ciencia matemática y docencia (2002), http://www.grupofederici.unal.edu.co/ bio/index.html (15 de abril de 2011).

Guerrero, Gerardo León. Universidad pública: modernización y modernidad 1826-1880. En: Revista Historia de la educación colombiana (1) (1998): 93-118.

Helg, Aline. La educación en Colombia 1918-1957. Una historia social, económica y política. Bogotá: Fondo Editorial CEREC, 1987.

. La educación en Colombia: 1946-1957. En: Nueva historia de Colombia (4) (1989): 111-158.

Henao, Myriam y Jorge Castro (comps.). Estado del arte de la Investigación en Educación y Pedagogía en Colombia, 1989-1999. Tomo I. Bogotá: Colciencias/Socolpe/ICFES, 2001.

Hernández, Carlos Augusto. Aproximación a un estado del arte de la enseñanza de las ciencias en Colombia, año 1999. En: Henao, Myriam y Jorge Castro (comps.). Estado del arte de la Investigación en Educación y Pedagogía en Colombia, 1989-1999. Tomo I. Bogotá: Colciencias/Socolpe/ICFES, 2001.

Herrera, Martha Cecilia y Carlos Low. Los intelectuales y el despertar cultural del siglo. El caso de la Escuela Normal Superior. Bogotá: Universidad Pedagógica Nacional, 1994. 
Herrera, Martha Cecilia (2000). La investigación educativa en la década del 80: Un esfuerzo cualitativo, http:// www.pedagogica.edu.co/storage/rce/articulos/21_20art.pdf (23 de septiembre de 2011).

Ibarra, Oscar. El sistema nacional de formación de docentes: el ejercicio docente como profesión (pp. 76-82). En: Sandoval, Sandra (comp.) La formación de educadores en Colombia. Geografías e imaginarios. Tomo I. Bogotá: Universidad pedagógica Nacional, 2001.

Lebot, Yvon. Educación e Ideología en Colombia (Medellín: Editorial La Carreta, 1975), http://www. mineducacion.gov.co/1621/articles-102524_archivo_pdf.pdf (23 de abril de 2011).

Martínez Boom, Alberto; Jorge Castro y Carlos Noguera.. Crónica del desarraigo, historia del maestro en Colombia. Bogotá: Magisterio, 1989.

Martínez de Dueri, Elba. Formación de educadores para una nueva Colombia. En: Revista Enfoques pedagógicos (1) (1994): 11-28.

Mejía, Marco Raúl. Leyendo las políticas educativas de la globalización. Presentación en el panel sobre reformas educativas en América Latina en el XX Congreso de la CIEC Santiago de Chile, enero 8-14 de 2004: http:// www.planetapaz.org/campanas/educacion/politicas_educativas.pdf ( 6 de julio de 2008).

Ministerio de Educación. República de Colombia. Educación colombiana. 1903-1958. Tomo I. Bogotá: Imprenta Nacional, 1959.

Misión de Ciencia, Educación y Desarrollo. Colombia: al Filo de la Oportunidad. Bogotá: Ministerio de Educación Nacional, 1994.

Molina, Adela; Carmen Alicia Martínez, Carlos Javier Mosquera y Lyda Mojica. Diversidad cultural e implicaciones en la enseñanza de las ciencias: reflexiones y avances. En: Revista Colombiana de Educación (56), 2009, p. 124.

Nieto Caballero, Agustín. Sobre el problema de la educación nacional. Bogotá: Ministerio de Educación Nacional, Ciencia y Cultura, 1937.

Obregón, Diana. La sociedad de naturalistas neogranadinos y la tradición científica. Anuario colombiano de historia social y de la cultura, 8 (18-19) (1990-1991): 101-123.

· (ed.). Culturas científicas y saberes locales: asimilación, hibridación, resistencia. Bogotá: Universidad Nacional de Colombia, 2000, http://www.bdigital.unal.edu.co/1274/2/01PREL01.pdf

Ocampo, Javier. Educación, Humanismo y Ciencia. Historia de las Ideas Fundamentales en el desarrollo de la Universidad Pedagógica y Tecnológica de Colombia. Tunja: Ediciones La Rana y el Águila (1978).

. Orígenes de las Universidades Pedagógicas en Colombia. En: Revista Historia de la Educación Colombiana (1) (1998): 183-197.

. Las huellas de Mutis y Humboldt en la ciencia y educación colombianas. En: Revista Historia de la Educación Colombiana (2) (1999): 11- 43.

.El Dr. José Félix de Restrepo: el maestro de la generación de independencia. En: Revista Historia de la Educación Colombiana (6-7) (2004): 9-54.

Ocampo, Javier. Rafael Bernal Jiménez. Sus ideas educativas, sociológicas, humanistas y la Escuela Nueva en Boyacá. Bogotá: Plaza \& Janés, 2001.

Ospina Rodríguez, Mariano. Exposición del Secretario del Despacho del Interior ante el Congreso. Bogotá: Imprenta Cualla, 1842.

Ortiz, Raúl y Juan Pablo Suárez. La formación de maestros y la noción de maestro investigador (1996-2005). Un espacio para la reflexión y el debate. Medellín, Universidad de Antioquia, 2009 (Tesis de Maestría).

Parra, Lina Adriana. Los orígenes de la Universidad Pedagógica de Colombia - Tunja. En: Revista Rhela, 6 (2004): 165- 178.

Poveda, Gabriel. Cien años de ciencia en Colombia. En: Enciclopedia Nueva Historia de Colombia (Tomo IV. pp. 159-188). Bogotá: Planeta editorial, 1989.

Quiceno, Humberto. Movimiento Pedagógico, posición crítica y lugar de liberación (pp. 95-128). En Suárez, Hernán y Abel Rodríguez, A (comps.). 20 años 1982-2002 del movimiento pedagógico entre mitos y realidades. Bogotá: Cooperativa Editorial Magisterio/Corporación Tercer Milenio, 2002. 
Radke, Francisca. Historia del Instituto Pedagógico Nacional para señoritas desde 1927 hasta 1935. Bogotá: Editorial El Gráfico, 1936.

Reglamento de la Facultad Ciencias de la Educación. Tunja: UPTC, 1934.

Ríos, Rafael. De la pedagogía a las ciencias de la educación: una lectura desde el saber pedagógico colombiano. En: Revista Educación y Pedagogía, 18 (44) (2006): 11-31.

Rodríguez, Abel. El Movimiento Pedagógico un encuentro de los maestros con la pedagogía (pp. 15-60). En Suárez, Hernán y Abel Rodríguez (comps.). 20 años 1982-2002 del Movimiento Pedagógico, entre mitos y realidades. Bogotá: Cooperativa Editorial Magisterio/Corporación Tercer Milenio, 2002.

Saldarriaga, Oscar; Javier Sáenz y Armando Ospina. Mirar la infancia: pedagogía, moral y modernidad en Colombia, 1903-1946. Bogotá: COLCIENCIAS, 1997.

Saldarriaga, Oscar. Del oficio de maestro. Prácticas y teorías de la pedagogía moderna en Colombia. Bogotá: Cooperativa Editorial Magisterio, 2003.

. La escuela colombiana hace 200 años al derecho y al revés. Once relatos para contar. Bogotá: Ministerio de Educación Nacional, 2009 (Colección Bicentenario).

Silva, Renán. La inmigración docente como posibilidad histórica: El caso de la Universidad Nacional de Colombia, 1930 - 1950. En: Revista Sociedad y Economía (15) (2008): 169- 195.

Soto, Diana. Mutis y los estudios matemáticos en Santafé de Bogotá. En: Colombia Revista Ciencias de la Educación (26) (1992): 28 - 31.

. Francisco Moreno Escandón reformador de los estudios superiores en Santafé de Bogotá. En: Revista Historia de la Educación Colombiana (1) (1998): 39-51.

. Aproximación histórica a la Universidad colombiana. En: Revista Historia de la Educación Latinoamericana (7) (2005): 99-136.

Suárez, Hernán y Abel Rodríguez (comps.). 20 años, 1982-2002, del Movimiento Pedagógico, entre mitos y realidades. Bogotá: Cooperativa Editorial Magisterio/Corporación Tercer Milenio, 2002.

Wasserman, Moisés. La ciencia en Colombia en 200 años de vida republicana (pp. 8-19). En: Colección Colombia 200 años de identidad. Tomo V. Para pensar a Colombia. Bogotá: Universidad Nacional/Publicaciones Semana, 2010.

Zambrano, Armando. Asamblea Fundacional de la Asociación Colombiana para la Investigación en Educación en Ciencias y Tecnología (EDUCYT). Ibagué: Universidad del Tolima, 2009.

Política de ciencia y tecnología, redes académicas e implicaciones para la educación. Memorias del Primer Congreso EDUCYT, 2009, http://www.educyt.org/portal/index.php?option=com_k2 \&view=ite mlist\&layout=category\&Itemid=15 (23 de mayo de 2010).

Zapata, Ramón. Dámaso Zapata o la reforma educacionista en Colombia. Bogotá: Editorial El Gráfico, 1960.

Zuluaga, Olga Lucía. Pedagogía e Historia. Bogotá: Foro Nacional por Colombia, 1987.

. La investigación histórica en la pedagogía y la didáctica. En: Zuluaga, Olga et al. Objeto y método de la pedagogía (pp.119-125). Medellín: Departamento de Pedagogía, Facultad de Educación, Universidad de Antioquia.

435-447.

. Historia del saber pedagógico. En: Revista Educación y Pedagogía, 7 (14-15) (1995/1996):

Zuluaga, Olga; Alberto Echeverry; Alberto Martínez; Stella Restrepo y Humberto Quiceno. Educación y pedagogía, una diferencia necesaria. En: Revista Educación y Cultura (14) (1988): 4-9.

. Pedagogía, didáctica y enseñanza. En: Revista Educación y Cultura (14) (1988): 10-11.

Zuluaga, Olga Lucía y Alberto Martínez Boom. Historia de la educación y de la Pedagogía: desplazamientos y planteamientos (pp. 55-75). En: Martínez Boom, Alberto y Mariano Narodowski (eds). Escuela, historia y poder. Buenos Aires: Ed. Novedades Educativas, 1996-1997. 


\section{Constituciones}

Constitución de 1821. Congreso General de Cúcuta, http://bib.cervantesvirtual.com/servlet/ SirveObras/ 01361686446795724200802/p0000001.htm\#I_1

Constitución Política de los Estados Unidos de Colombia de 1863. Convención Nacional. Congreso de Ríonegro, http://bib.cervantesvirtual.com/servlet/SirveObras/07030730122947295209079/p0 000001.htm\#I_1_ Constitución de 1886. Consejo Nacional Constituyente, ftp://ftp.camara.gov.co/camara/basedoc/cp/constitucion_politica_1986.html

Constitución Política Colombiana de 1991. Asamblea Nacional Constituyente, http://web.presidencia. gov. co/constitucion/index.pdf

\section{Leyes}

Ley Orgánica de Educación Pública de 1826. República de Colombia.

Ley 66 de 1867 Por la cual el Congreso de los Estados Unidos de Colombia, la organización de una Universidad en la capital de la República, la que llevará el nombre de "Universidad Nacional de los Estados Unidos de Colombia”, http://www.legal.unal.edu.co/sisjurun/normas/Norma1.jsp?i=34584

Ley 30 de 1868. República de Colombia. Codificación Nacional de todas las Leyes desde el año 1821. 24 tomos. Bogotá: Imprenta Nacional, http://www.consejodeestado.gov.co/seminario/Documentos_Seminario/ algunos_ejemplos_ultimo.pdf

Ley 39 de 1903. Ley Orgánica de Instrucción Pública, http://www.mineducacion.gov.co/1621/articles-102524_archivo_pdf.pdf

Ley 29 de 1990. Por la cual se dictan disposiciones para el fomento de la investigación científica y el desarrollo tecnológico y se otorgan facultades extraordinarias, http://www.colciencias.gov.co/sites/default/ files/upload/reglamentacion/ley_29_de_1990.pdf

Ley 30 de 1992, por la cual se organiza el servicio público de la Educación Superior. Congreso de la República de Colombia, http://www.mineducacion.gov.co/sistemasdeinformacion/1735/articles-211884_Ley_30.pdf

Ley 115 de 1994 por la cual se expide la Ley General de Educación. Congreso de la República de Colombia, http://www.mineducacion.gov.co/1621/articles-85906_archivo_pdf.pdf

Ley 715 de 2001, por el cual se dictan disposiciones para organizar la prestación de los servicios de educación... Congreso de la República de Colombia, http://www.mineducacion.gov.co/1621/articles-86098 _archivo_pdf.pdf

Ley 1188 de 2008, por el cual se regula el registro calificado de programas de Educación Superior y se dictan otras disposiciones. Congreso de la República de Colombia, http://www.mineducacion. gov.co/1621/ articles-159149_archivo_pdf.pdf

Ley 1286 de 2009, por la cual se modifica la Ley 29 de 1990, se transforma a Colciencias en Departamento Administrativo, se fortalece el Sistema Nacional de Ciencia, Tecnología e Innovación en Colombia y se dictan otras disposiciones. Congreso de la República de Colombia, http://www.colciencias.gov.co/sites/ default/ files/upload/reglamentacion/ley_1286_de_2009.pdf

\section{Decretos}

Decreto Orgánico de Instrucción Pública DOIP, 1870. Presidencia de los Estados Unidos de Colombia, http:// www.pedagogica.edu.co/storage/rce/articulos/5_8docu.pdf

Decreto reglamentario 491 de 1904, por el cual se reglamenta la Ley 39 de 1903, sobre Instrucción Pública. Ministerio de Instrucción Pública, Colombia, http://www.mineducacion.gov.co/1621/articles-102515_ archivo_pdf.pdf

Decreto 1990 de 1933, mediante el cual el Gobierno Nacional Fundó oficialmente la Facultad de Ciencias de la Educación a nivel universitario, con una estructura y reglamentación para la que se fundó en Bogotá y la que ya funcionaba en Tunja desde 1928 para la formación del Profesorado de Segunda Enseñanza, http:// www.uptc.edu.co/facultades/f_educacion/pregrado/sociales/inf_adicional/

Decreto 1917 de 1935, por el cual la Facultad de Ciencias de la Educación queda dependiente de la Escuela Normal Superior de Bogotá, http://www.uptc.edu.co/facultades/f_educacion/pregrado/filosofia/inf_adicional/ Decreto extraordinario 080 de 1980, por el cual se organiza el sistema post-secundaria. Ministerio de Educación Nacional. República de Colombia, http://www.mineducacion.gov.co/1621/articles-102556_ archivo_pdf.pdf 